\title{
A Predictive Maintenance Cost Model for CNC SMEs in the Era of Industry 4.0
}

\author{
Kwaku Adu-Amankwa ${ }^{1}$, Ashraf K.A. Attia ${ }^{2}$, Mukund Nilakantan Janardhanan ${ }^{2 *}$, Imran Patel ${ }^{2}$ \\ ${ }^{1}$ Department of Design, Manufacture and Engineering Management, University of Strathclyde, United Kingdom. \\ ${ }^{2}$ Department of Engineering, University of Leicester, United Kingdom.
}

\begin{abstract}
Within the subject area of maintenance and maintenance management, authors identified a deficiency in studies focussing on the expected value from adopting Predictive Maintenance (PdM) techniques for Machine Tools $(M T)$ s. Authors identified no studies focusing on presenting a PdM value analysis or cost model specifically for Small-Medium Enterprise (SME)s operating Computer Numerically Controlled (CNC) MTs. This paper's novelty is addressing SMEs minimal representation in literature by explanatorily collecting data from SMEs within the focal area via surveys, modelling and analysing datasets, then proposes a cost effective PdM system architecture for SME CNC machine shops that predicts cost savings ranging from $£ 22,804-£ 48,585$ over a range of $1-50 \mathrm{CNC}$ MTs maintained on a Distributed Numerically Controlled (DNC) network. Affirms PdM's tangible value creation for SME CNC machine shops with predicted positive impacts on their MTs cost and performance drivers. These exploratory research findings corroborates SMEs pooling together to optimize their CNC MT maintenance cost through the recommended system architecture. Finally, introduces opportunities for further PdM research taking into account SMEs' perspective. The paper's industrial application is confirmed from the surveyed SMEs that demonstrated their current utility of PdM; then anonymous positive feedback on the online dashboard, shared with participant companies, confirmed the research results supported SMEs in considering exploring the path to adapting PdM. It is anticipated that beneficiaries of this research will be maintenance managers, business executives and researchers who seek to understand the expected financial and performance impact of adopting PdM for a MT's overall life cycle costs.
\end{abstract}

Keywords: Industry 4.0; Predictive maintenance; Machine maintenance cost; Machine tool

*Correspondence Email: mukund.janardhanan@leicester.ac.uk

\section{Introduction}

Industrial Revolution $(I R)$ in the late 18th century initiated key organisational developments and adaptation practices that enabled existing organisations cope with the ever-changing environmental factors and business requirements [1]. These changes make an IR potent towards transforming existing practices or tools to increase efficiency; therefore, improving manufacturing processes is key for transformations [2]. In the late 20th century, the emergence of computers, internet and robots which resulted in huge improvements to industrial processes by introducing concepts of automation which is popularly known as Third Industrial Revolution (3IR) or Digital Revolution [3]. The first decade of 21st 
century witnessed an introduction of new digital disruptive technologies that are being embraced as tools for the digital-industrial future; this concept can be been accredited to the German government's 2011 promotion of manufacturing computerisation, dubbed Fourth Industrial Revolution (4IR) or Industry 4.0 [4]. As IRs industrialise key manufacturing processes like production batches and lead time with improved Machine Tools $(M T)$ s, strategic efforts are required to keep these MTs in worthy operating conditions via maintenance procedures. Maintenance philosophies have also transformed over the generations from a necessary evil into a valuable performance driver. Figure 1 illustrates MTs and their associated maintenance evolutions throughout the IR eras.

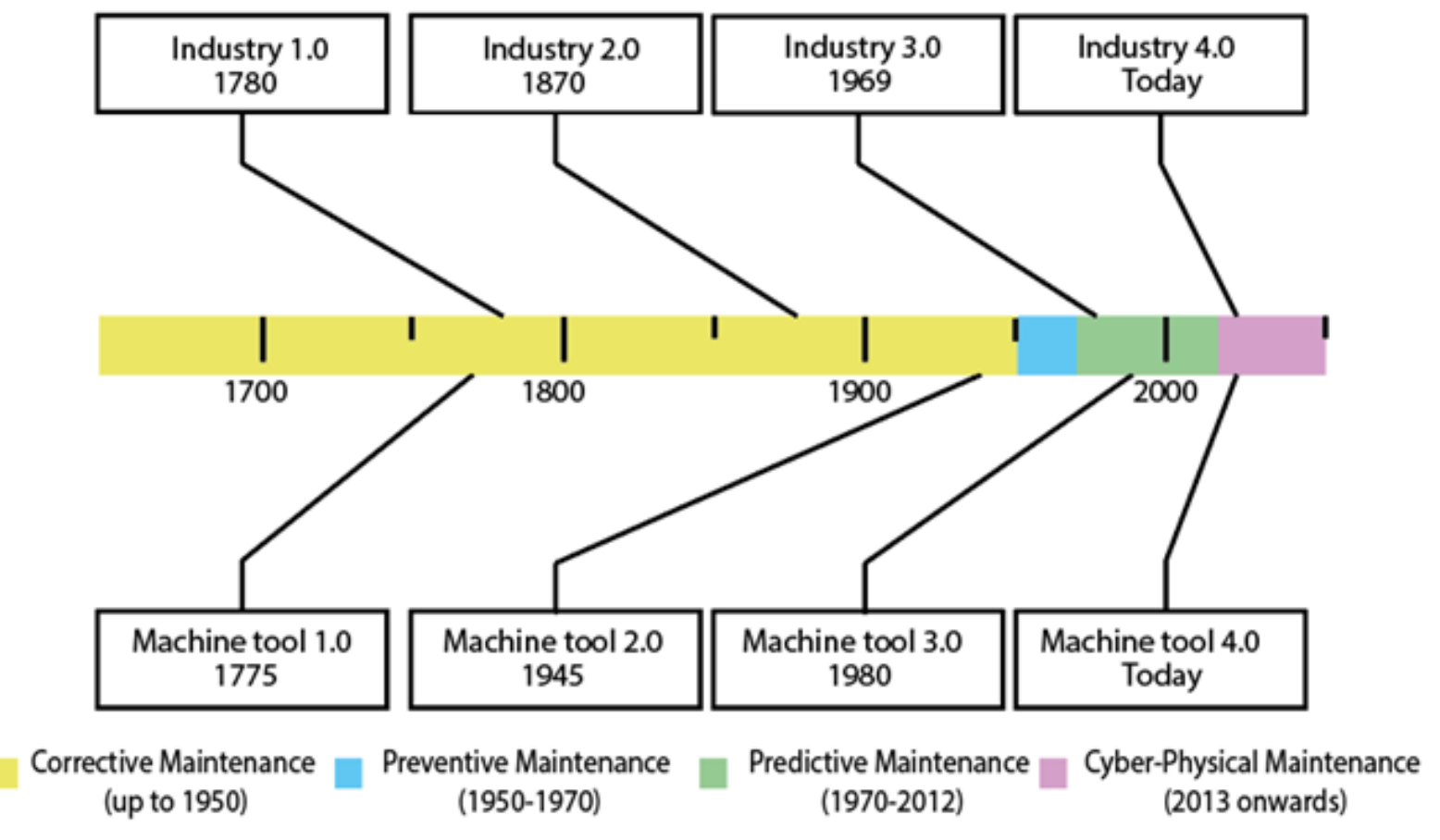

Fig. 1 Machine Tool and Maintenance Evolution over Industrialisation Eras

Industry 4.0 focuses on the ability of "smart" machines to perform autonomously and provide statistical data on their physical processes. The smart machine data is monitored by cyber physical systems $(C P S) \mathrm{s}$, which are equipped to make decisions based upon measured feedback via high-end sensors, microcontroller units and software [5]. Smart machines and factories use advanced technologies such as networking, connected devices, data analytics, and artificial intelligence to reach more efficient Predictive Maintenance $(P d M)$. $P d M$ involves networking and servicing machines before failure and attending to non-major faults to improve safety, reliability, availability, and efficiency [6-8]. These interactions form an ecology that supersedes 3IR, where automated machines worked independently under supervision of an operator, by having machines working and interacting together under minimal supervision of humans $[9,10]$.

MTs are major components of any manufacturing systems, they have evolved from manually operated machines into CNC MTs with the advent of computers in the 3IR. With the rapid integration of "Industry 4.0" within SMEs that utilises disruptive digital technologies like cloud computing, artificial intelligence and big data, a new generation of machines are building upon the concept of Distributed Numerically Controlled (DNC) machines, which was first coined in the 1980s [11]. 
However, during these transformations, there seems to be minimal consideration for the SME's when advanced technologies are discussed since several implementation methods are often too complex and capital intensive. This study seeks to contribute towards making appropriate PdM decisions suitable for SME CNC machine shops by identifying PdM's suitability, proposing a cost effective PdM DNC system architecture and affirming PdM's additional tangible value creation.

Maintenance management reviews by Ruschel et al. [12] and Garg and Deshmukh [13] revealed relatively few articles reported on maintenance costing aspect for management decision; therefore, this study seeks to contribute in that deficiency area too. This study also aims to further develop a cost model that will assist SME machine shops to evaluate benefits of adopting PdM techniques, using financial modelling and strategies that build on maximizing value. This was achieved by collecting and analysing data from SME CNC machine shops in the United Kingdom (UK) that utilizes PdM techniques and their impact on the cost performance. A reusable interactive platform has been developed and will be published online for the benefit of SME CNC machine shop companies when making informative decisions regarding investing into PdM initiatives and projects. The UK government is strategically aligning towards "Industry 4.0" concepts, as can be seen from the document entitled "Factory of The Future" [14]. However, there is no public platform that SMEs can easily access or use to assist in their investment decisions for "Industry 4.0" techniques, and to effectively estimate their CNC MTs maintenance cost within the Total Cost of Ownership (TCO) and Life Cycle Costs (LCC).

The overall goal and scope of this study is to extend the PdM body of knowledge by capturing the potential readiness, voice and perspectives of SMEs operating CNC MTs using relatively simple and logical relationships and discovered themes. This exploratory research approach commenced with reviewing literature for key PdM cost drivers, acquiring primary data from SMEs across UK; then analysing this data for inferences against benchmarks in literature. Ultimately this study proposes a need for such PdM technologies research to incorporate the perspectives of SMEs and recommends adaptation measures for SMEs; supported with predicted values on tangible gains and constraints of adopting PdM at the SME level through the proposed system architecture. An argument was put forth as a research agenda calling for further studies in that area because it was discovered that SMEs were using PdM and their situation was unique from other larger organisations.

\section{Literature Review}

This section discusses trends concerning maintenance and its management, then identifies the research gap and how this paper's novelty contributes to filling this gap.

\subsection{Maintenance and Maintenance Management}

Maintenance and Maintenance Management are no new topics in the field of academic and industrial practice. Although meaningful literature on maintenance impact is abundant, Bokrantz et al. [6] argued that manufacturing literature often side-line maintenance's specific readiness for the forthcoming 
"Industry 4.0"; therefore, their study revealed the gap between the expectations of digitalised manufacturing and the future role of maintenance. This section reviews the maintenance impact and its evolution over the years.

After investigating various maintenance strategies, authors identified four main strategies trending in the literatures, that being Corrective Maintenance $(C M)$, Preventive Maintenance $(P M)$, Predictive Maintenance $(P d M)$ and Cyber-Physical Maintenance (CPM). CM is simply maintenance performed in reaction to unplanned functional capabilities failure ("malfunction") [15,16]. CM has huge cost implications; thus, is often deemed a major maintenance classification in several literatures $[17,18]$.

Unlike CM, PM tackles problems of imminent failure by performing scheduled maintenance [7,18]; thus, PM is often deemed as the next major classification of maintenance [7,12]. PM is deemed as a valueadding activity [19,20]; however, PM's pre-programmed intervention by the Original Equipment Manufacturer $(O E M)$ risks tampering with machine performance by influencing faster deteriorating states [21]. Furthermore, Galar et al. [19] cautioned on this similar problem of repeated cycles of PM without adding value to machine's availability and reliability and suggest that both CM and PM can induce irrelevant downtime and affect the equipment's LCC. Therefore, they proposed using "smart" maintenance services that migrate from fail to fix into predict and prevent philosophies. This is where PdM value can be underlined.

$\mathrm{PdM}$ is a proactive process of performance modelling and conditional monitoring used to trigger warnings for effective maintenance scheduling and execution [10,20]. Additionally, Mobley [17] identified PdM as opportune activities for improving productivity, product quality, and overall effectiveness of manufacturing, by regularly monitoring equipment operating conditions (e.g. efficiency, capability, etc.). The rapid development of predictive science, prognosis as a valuable tool, is useful in predicting service life of MT and this leads to an efficient maintenance strategy [10,21]. Recent technological advancements for 4IR have resulted in proposed cloud-based PdM services to augment Industrial Internet of Things (IoT) for collecting and transmitting condition measurements to a centralized server for analysis, fault diagnosis, prognosis and maintenance scheduling [23,24].

CPM seeks to extend PdM and is deemed as Intelligent Maintenance for monitoring interconnected systems through digital-twining; thus, enabling a maintenance approach that brings the digital and physical worlds together to create an intelligent network [22-24]. Lee [25] argued that digital-twinning is an intersectionality and not a union of physical and cyber infrastructure; therefore, CPM requires both aspects of physical and cyber maintenance. Furthermore, Brettel et al. [26] argued industrial revolutions were triggered by technical innovation; while 4IR is triggered by Cyber-Physical System (CPS), enabling close monitoring of information flow and synchronization with physical equipment and cyber space. The advent of industrial IoT and industrial big-data have resulted in significant new opportunities, as well as challenges to maintenance. Therefore, CPM can be seen as an embodiment of PdM for self-healing systems [25]. 
Academic and industrial reviews were consulted which included 111 academic papers and 18 case studies from industrial resources including consulting organisations in the field such as IBM [27].

This section presents re-categorised papers from strategic literature reviews by Ruschel et al. [12] and Garg and Deshmukh [13] as CM, PM, PdM and CPM, in conjunction with the literature used in this study to establish trends shown in Figure 2. This was accomplished by reassessing papers in the strategic literature review to determine the trending maintenance literature as perceived from current day perspectives. The trends in Figure 2 observing vital years (2006, 2017 and 2018) reveal a significant increasing trend in PdM, a steep increasing trend in CPM, a reducing tend in PM and an almost stagnated trend in CM. The overall trend demonstrates significant increase and justification to explore PdM for this research study.

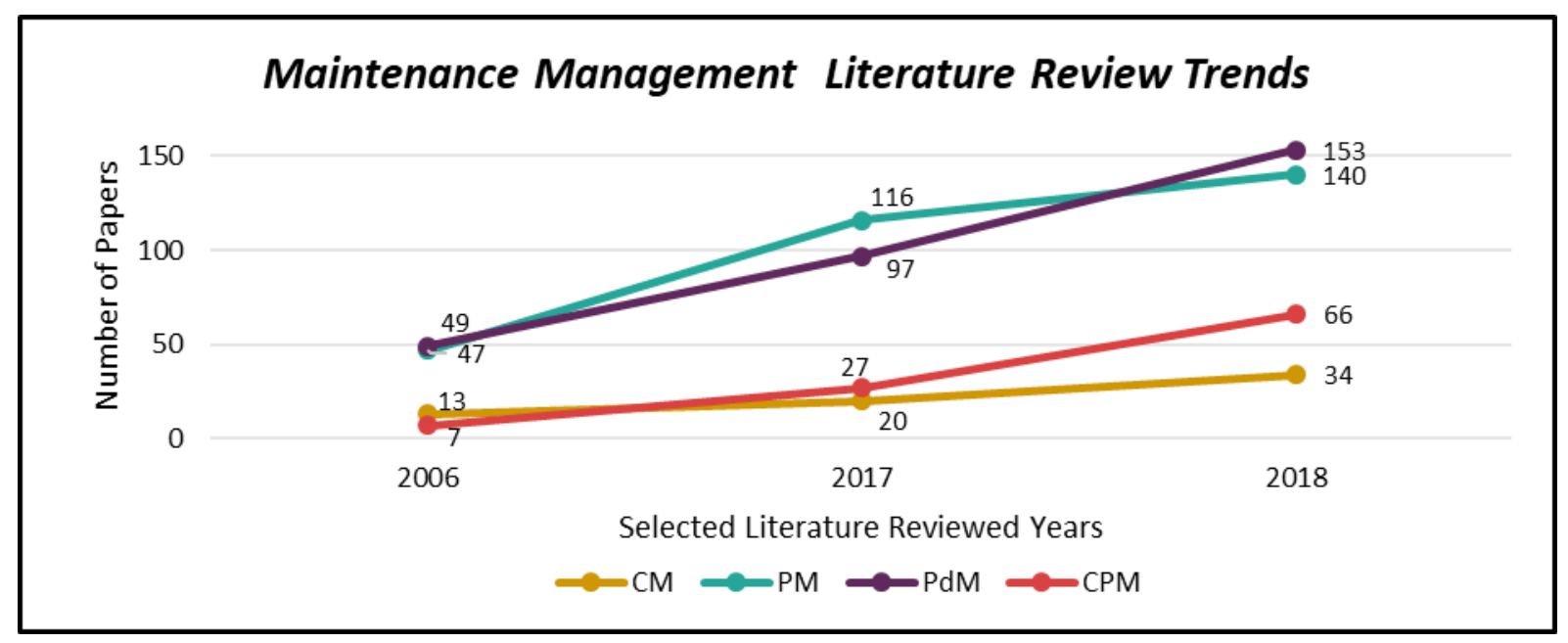

Fig. 2 Maintenance Management Literature Review Trends Chart

The following section discusses benefits and challenges of PdM as reported in reviewed literature earlier. Mobley [28] surveyed successful PdM programmes and revealed anticipated improvements upon implementing PdM. Similarly, IBM [27] identified benefits of implementing PdM for the anticipated 4IR. The Table 1 highlights predicted results deemed relevant for MT users, while Figure 3 demonstrates predicted significant cost reductions when migrating through maintenance types [30,32].

Table 1: Benefits of Adopting Predictive Maintenance (Predicted Values)

\begin{tabular}{|c|c|c|}
\hline Benefits & Mobley (2001) & IBM (2016) \\
\hline Decrease in Maintenance Costs & $50 \%$ & $50 \%$ \\
\hline Breakdowns Eliminated/Reduced & $55 \%$ & $70 \%$ \\
\hline Increase in Mean Time Between Failure (MTBF) & $30 \%$ & $50 \%$ \\
\hline Increase in Machine Uptime & $30 \%$ & $35 \%$ \\
\hline
\end{tabular}

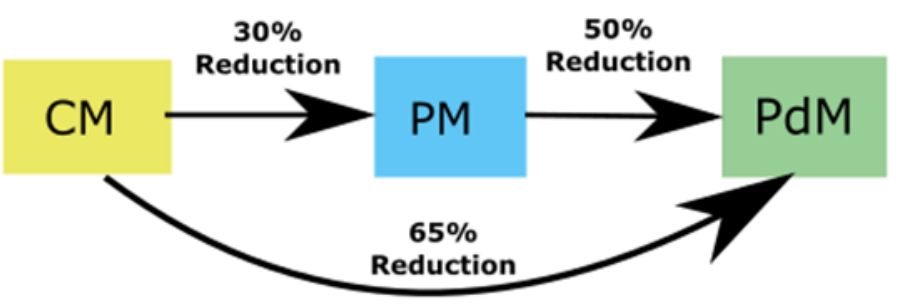

Fig. 3 Maintenance Cost Reduction Process (Predicted Values) 
Although PdM programmes promise significant benefits, Table 2 maps a summary of the additional responsibilities and challenges of PdM as argued by Mobley [17] and Galar et al. [19].

Table 2 Challenges of Adopting Predictive Maintenance (Described Issues)

\begin{tabular}{|c|c|}
\hline Challenges & Brief Description \\
\hline $\begin{array}{l}\text { Unreliable Data or Calibration } \\
\text { Error }\end{array}$ & $\begin{array}{l}\text { ad taking } \\
\text { g failure }\end{array}$ \\
\hline $\begin{array}{l}\text { Special Training Required and } \\
\text { Costs for System Analysis }\end{array}$ & $e^{2}$ \\
\hline $\begin{array}{l}\text { Maintenance and Security of Data } \\
\text { Infrastructure }\end{array}$ & $\begin{array}{l}\text { y requirements to ensure } \\
\text { leaked or hacked maliciously }\end{array}$ \\
\hline $\begin{array}{l}\text { Significant Investments on } \\
\text { Acquisition Cost }\end{array}$ & $\begin{array}{l}\text { Initial investment into the technological infrastructure can } \\
\text { be significant, when retrofitting to factory's original design }\end{array}$ \\
\hline
\end{tabular}

\subsection{CNC Machine Tool Cost Models}

For CNC MTs, TCO comprises "Operating Costs" and "Maintenance Cost"; thus, maintenance costs contribute to lifecycle costs via Programmed Maintenance (Preventive) and Un-programmed Maintenance (Corrective) [29]. Furthermore, Enparantza et al. [29] demonstrated the limitations of cost models that are applicable to MT by stating: "A basic feature of a LCC tool for machine tools is the evaluation of maintenance costs which are based on the (Reliability, Availability and Maintainability) RAM parameters of the machines" [29].

Whereas Parida et al. [30] reviewed maintenance performance literature to affirm maintenance cost drivers are influenced by tangible and intangible inputs (e.g. IT support). They supported their argument on maintenance's metrics by stating excessive breakdown and CM adversely affect performance, while PM and PdM drive both performance and costs when effectively applied.

Moreover, Reina et al. [31] re-constructed previous authors' concerns by discussing the cradle-to-grave perspective of LCC in manufacturing systems. They revealed maintenance as an essential contribution towards LCC and affirmed its potentials towards reducing overall LCC in manufacturing industries. They built upon Enparantza et al.'s [29] recommendations on RAM parameters by establishing that reliability and maintainability are strongly interconnected as influential cost drivers in LCC, so an effective maintenance strategy can influence the MT's useful life and in turn reduce LCC. Reliability and Maintainability $(R \& M)$ costs were highlighted as major cost drivers in manufacturing. The highlighted reliability related costs were associate with lost production from operations; while the highlighted maintenance costs were associated with scheduled maintenance (preventive/predictive), unscheduled maintenance (corrective) and spare parts (inventory).

Despite the popularity of PdM in various literatures, the majority of academic literature focuses on maintenance optimisation through reliability tools and complex mathematical R\&M relationships for $\mathrm{PdM}$, through conditional or statistical monitoring of equipment health, yet, limited work have been reported on the actual maintenance cost. Likes of Enparantza et al. [29] have demonstrated research need towards CNC MT cost models and even identified existence of such systems within business-to-business domains, for example automobile industries. Kans and Ingwald [32] proposed a maintenance database 
concept to support costing; while Cheng et al. [33] proposed a distributed network manufacturing environment with a focus mostly on the technological development. The reviewed literature indicate trends towards PdM adaptation or optimisation from reliability engineering perspectives, with few on the efforts to reduce LCC for CNC MTs. Furthermore, this paper reveals scarcity of MT maintenance cost literature tailored for SMEs and proposes a cost model that will assist SMEs with maintenance strategic decisions in "Industry 4.0" towards evaluating expected value of PdM for their CNC MTs LCC.

\section{Research Methodology}

From a conceptual and theoretical perspective, this field of research using data technology for PdM is relatively new. This study identified no major theory or framework regarding PdM's adaptation impact on SME CNC shops that was readily available. Nevertheless, secondary data presented in the public case studies and previous literature on PdM's impact composed a reasonable direction for testing.

Although secondary data lacked similar costing projects on implementing PdM for CNC MTs; it provided direction that was used to confirm industrial consensus on cost impacts of adopting PdM for various industries. According to Bryman and Bell [34], using secondary data has several advantages. It saves the researcher cost and time, provides high-quality source to solidify the research, provides different opportunities for multiple analysis methods, and forms a good opportunity for cross-cultural analysis.

Primary data was gathered using questionnaires disseminated to SME CNC shops in the UK to reduce the impact of unavailability of historical data. Upon reviewing secondary data and conducting literature review, the primary hypotheses were developed and accordingly an initial questionnaire draft was constructed and reviewed. An online survey platform was selected for easy distribution and increased reliability. The main questions included in the research questionnaire were Likert-type scale questions collected using Self-Administered Questionnaires (SAQ) distributed to candidates in the UK, and a total of 21 responses were received from SMEs and further investigated for this research study.

\subsection{Key Hypotheses}

The key hypotheses investigated for the paper were as follows:

(H1) Feasibility of adopting PdM for SME CNC machine shops in "Industry 4.0"

(H2) Cost effectiveness for SME CNC machine shops to use PdM

(H3) Implementing PdM outcomes in a tangible value creation for SME CNC machine shops

\subsection{Data Analysis}

Quantitative analysis was performed on the collected data in order to examine the impact of using traditional maintenance approaches, Corrective Maintenance $(C M)$ and Preventive Maintenance $(P M)$, and the expected or realised benefits of adopting PdM. The correlation between current maintenance state, various categories of maintenance costs, and the estimation results allowed a better understanding of the 
impact. Survey responses were exported to a spreadsheet software (Microsoft Excel) and statistical analysis software (SPSS) for detailed analyses and graphical representation of trends.

Correlation Analysis was used to investigate the bivariate relationship strengths and directions of each pair of selected variable using the Pearson product-moment correlation, supported by Cohen's [35] guidelines on interpreting the "Pearson's r" relationship [37]. Linear regression analysis was used to investigate the relationship between variables because it surpasses correlation, which gives a goodness of fit and direction, by providing a simple linear relationship of connected predictor variable for a possible outcome [39]. Additionally, the chosen multivariate regression is recommended by Panik [37] as an objective method of testing hypothesis with a measure of significance; since cost was not the only predictive parameter [41]. The Likert-Type Analysis was employed in assessing relationships among SME's opinion on the subject matter and its impact on their organisation's performance, to mitigate a misuse of these opinion as facts as cautioned by Robertson [43]. Pareto Analysis was used to complement the Likert-Type Analysis by prioritising the common cause process relationships between existing maintenance strategy and its overall impact of key performance indicators like cost, quality, safety and productivity [45]. Parametric Modelling was finally used to extend all the aforementioned analysis outcomes and literature in accordance with Todman and Dugard's [47] decision tree for small sample size statistical analysis and Mislick and Nussbaum's [49] cost estimation recommendation. The model's output were then used to develop a user-friendly dashboard using Power BI in order to extend the research finding's accessibility into the public domain. The research data shall be made available via Research Gate.

\section{Data Results and Analysis}

This section presents survey results for further analysis on inferred maintenance impact within participant companies. A preliminary breakdown of the 21 survey responses showed:

- 15 participants owned the CNC MT, thus were directly affected by maintenance costs

- Four participants leased the CNC MT, thus were indirectly affected by maintenance costs

- Two responses were considered void due to incomplete data to fully extract and process

\subsection{Preliminary Raw Data Result}

This section presents results from the raw data acquired in a synthesised manner to aid facilitated the reader's understanding and appreciation of the research findings and decisions leading to the analysis.

\subsubsection{Maintenance Strategies and Asset Size}

Survey responses provided meaningful data into contextually classifying their relevance towards the previously outlined hypotheses $(H 1-H 3)$ on investigating MT maintenance costs influence on its LCC. The 15 SMEs that owned their MT were assumed as principal stakeholders of TCO in terms of the impact of maintenance management and MT operations costs. Figure 4 represents a distribution of CNC MT 
maintenance strategies used by SMEs. $P M$ was the highest strategy employed (67\%), while PdM was the least employed (14\%). Figure 5 represents a distribution of participants' CNC MTs quantity on SMEs shop floor. The combined range of 1-5 MTs (47\%) and 5-10 MTs (21\%); jointly, represent over 60\% of responses; thus, bringing more evidential perspective towards few CNC MT on SME shop floor

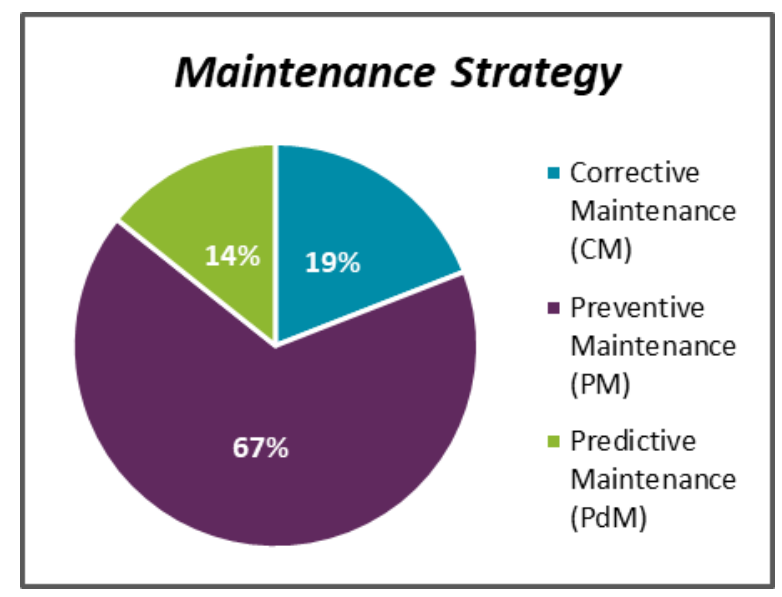

Fig. 4 Maintenance Strategies for SME CNC MT

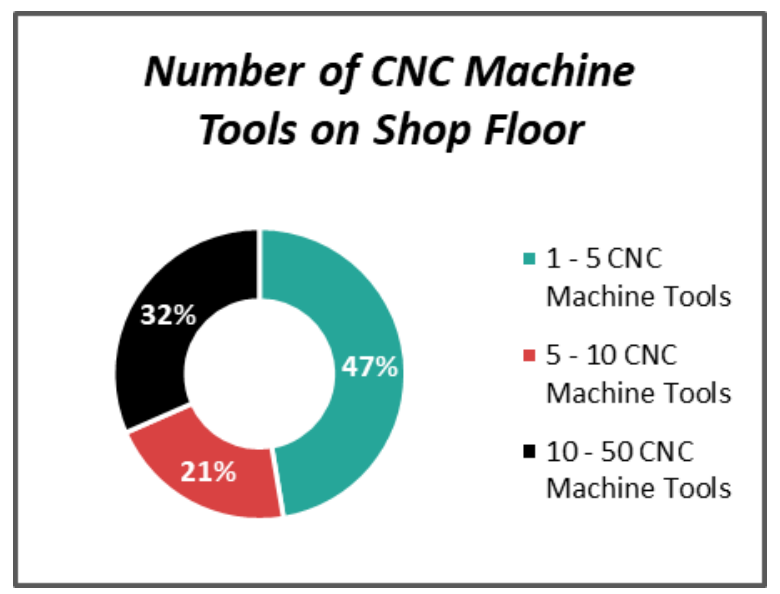

Fig. 5 CNC MT Quantity on SME Shop Floor

\subsubsection{Machine Performance Data Extraction}

The SME responses to data collection on MT performance via sensors revealed that $68 \%$ of SMEs did not participation in MT performance data extraction, 21\% of SMEs demonstrated "few" or "some" MT performance data collection, while $10 \%$ disclosed "mostly" or "completely" integrated data collection on MT performance. This information suggests an influence on MT breakdowns.

\subsubsection{Machine Operating and Failure Rates}

Majority of SMEs operates either 24-hours or 8-hours but shows an almost even distribution of shifthours throughout the day. The MT failure frequency was mostly "high", with a combined majority $(70 \%+)$ having frequent breakdowns in a month or less, and this may suggest frequent maintenance activities as drivers of cost. In building the argument towards maintenance impact significance from the perspective of "owned” or "leased” CNC MTs.

\subsubsection{Maintenance Costs}

Respondents' cost data revealed CNC MT total maintenance cost range from approximately $£ 10,000$ $£ 60,000$ annually, with an overall annual mean and median cost as $£ 34,737$ and $£ 30,000$ respectively, combining both categories of owned and leased CNC MTs. Figure 6 illustrates the broken-down nature of responses per category, thus revealing annual maintenance cost for leased MTs are approximately $£ 10,000$. Meanwhile maintenance cost for owned MTs range from approximately $£ 20,000-£ 60,000$ annually. The data set's overall 85 -percentile reveals that $15 \%$ of maintenance annual cost from the participants are higher than $£ 56,143$ or approximately close to the $£ 60,000$ category. This information confirms maintenance cost on CNC MTs as significant LCC and cost savings in this area will be of significant value for SMEs. 


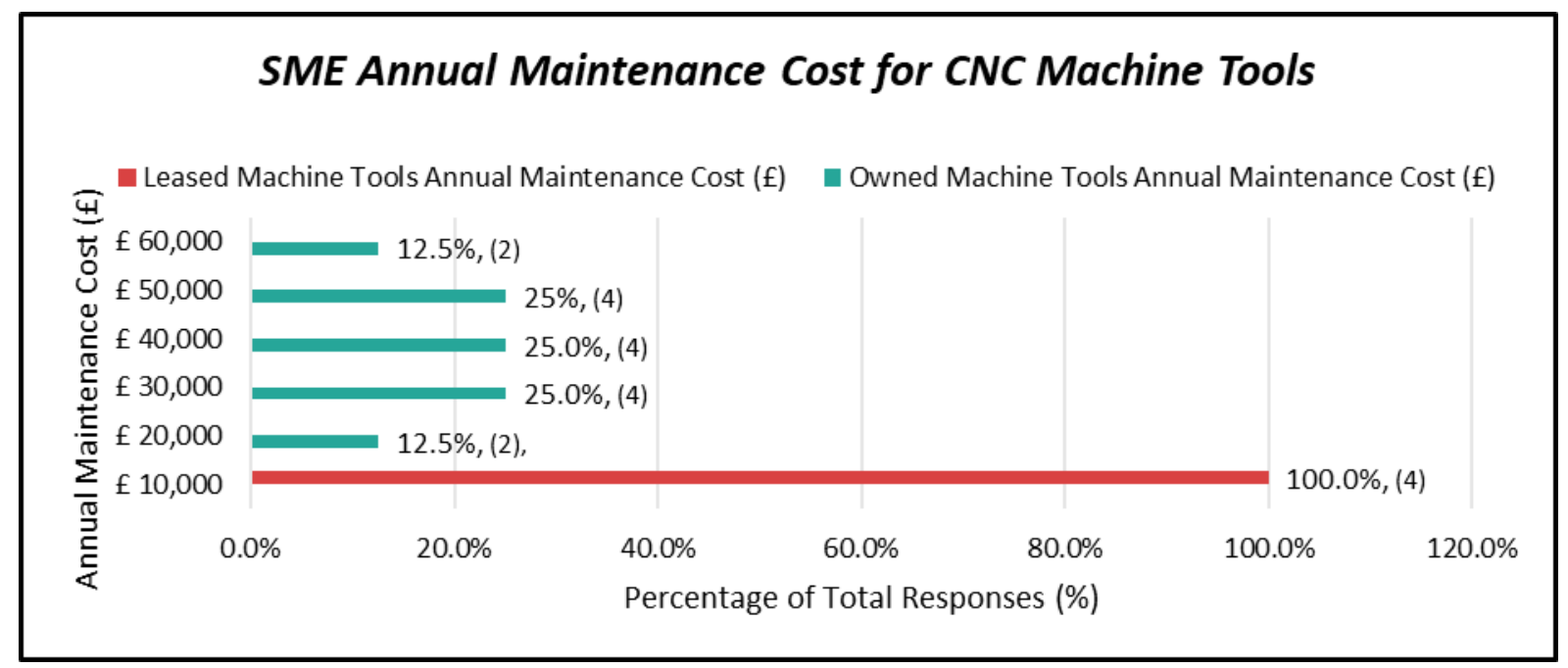

Fig. 6 Annual Maintenance Cost (£) of SME CNC Companies Bar Chart

Two respondents provided no maintenance cost information; thus it was assumed that those participants had no financial obligation towards CNC MTs maintenance due to their contracting terms or there was no financial information about company expenditure on their CNC MT maintenance. Furthermore, the cost trend of leased CNC MTs suggested respondents either had 'contractual knowledge' of the leasing company's maintenance expenditure on the CNC MT or paid an agreed amount to the leasing company for a maintenance package. This explains the lower limit values of the costs as compared to SMEs that own their CNC MTs.

\subsubsection{Likert-Type Scale Survey Results}

This section presents the survey results on key maintenance performance parameters (maintenance cost contribution, lost productivity cost, downtime cost and maintenance effectives). The charted results of Likert-Type scale questions are presented in Figure 7, which shows the maintenance cost significance via opinion responses for comparison with key maintenance costs and performance parameters.

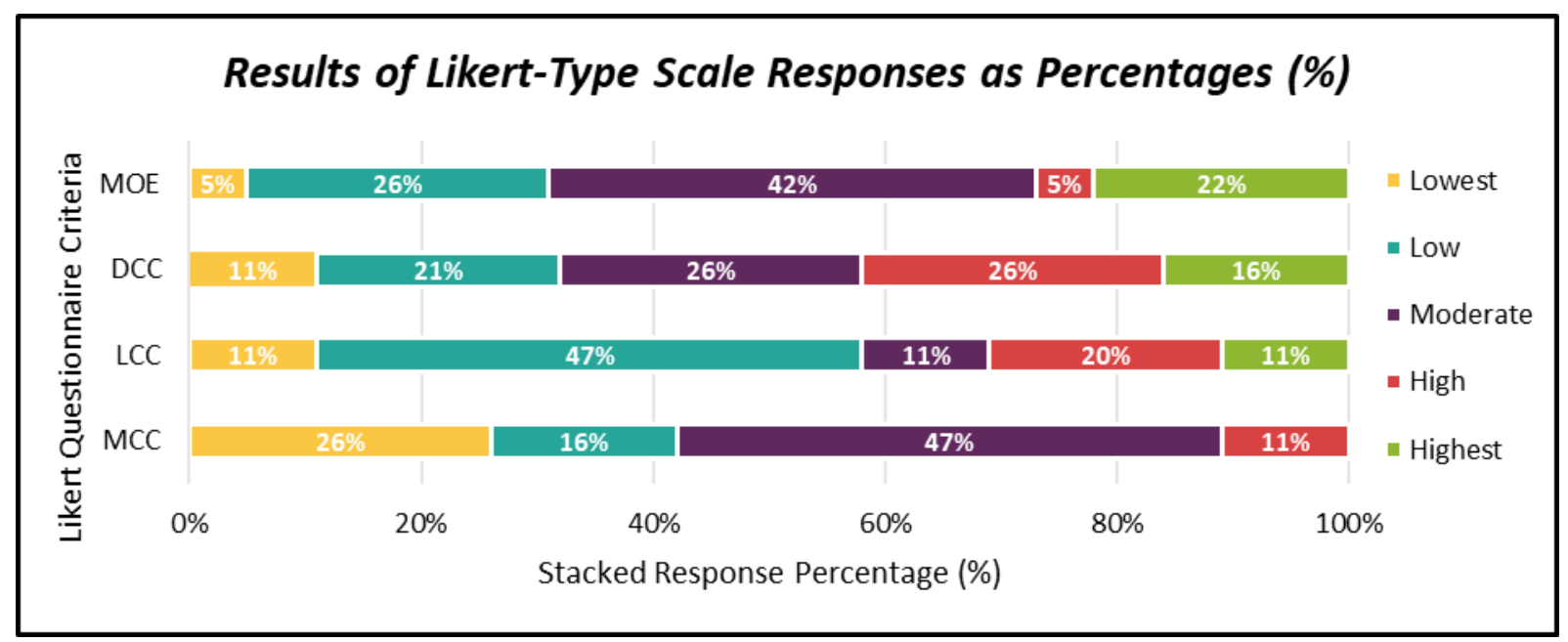

Fig. 7 Likert-Type Scale Survey Resolution as Stacked Bar Chart

Maintenance Cost to Operational Cost relationship (MCC) rating was mostly "Moderate" and represented $47 \%$ of responses in that category. This eluded the high maintenance costs disadvantage of CNC MT by Bawa [36], because "High" and "Highest" rates were the least, representing 11\% and 0\% respectively. Lost Productivity Cost to Maintenance Cost relationship (LCC) rating was mostly "Low" 
and represented $47 \%$ of responses in that category. Next in rank were "High" and "Highest" each representing $20 \%$ and $11 \%$ respectively. These responses demonstrate alignment with issues like production capacity management or calibration issues, which maintenance can address and improve [38,40]. Downtime Cost to Maintenance Cost relationship (DCC) rating was mostly "High" and "Moderate", and both represented 52\% of responses in that category. This verifies claims by Ungureanu et al. [42] that a major component of maintenance costs is due to malfunction or none productivity of CNC MT, known as downtime; as such downtime cost must be factored into maintenance costs. Maintenance Effectiveness rating (MOE - Uptime to Downtime relationship) was mostly "Moderate", followed by "Low", and these represented $42 \%$ and $26 \%$ of responses respectively in that category. This reveals overall equipment effectiveness relationship with Reliability, Availability and Maintainability (RAM) parameters that Enparantza et al. [29] mentioned as significant cost contributors for CNC MTs. The result of Likert-Type scale questions demonstrates areas of agreement and disagreement with popular literature claims, and this may suggest that SMEs' approach to CNC MT maintenance is unique-in-class.

\subsubsection{Motives for Adopting Predictive Maintenance (PdM)}

SMEs which identified their current maintenance system as PdM, were given further questions to facilitate in-depth understanding of motives that influenced adopting PdM as shown in Figure 8. These results confirmed suggested benefits of adopting PdM for CNC MTs by Mobley [17] and Selcuk [7]. Furthermore, from a CNC MT LCC perspective, these results suggest long term benefits of effective maintenance strategy. By focusing on areas like reliability, productivity, safety, quality and cost, an organisation tends to benefit from PdM as proposed by Houshyar [44,46], Okoh et al. [48] and Gu et al. [50].

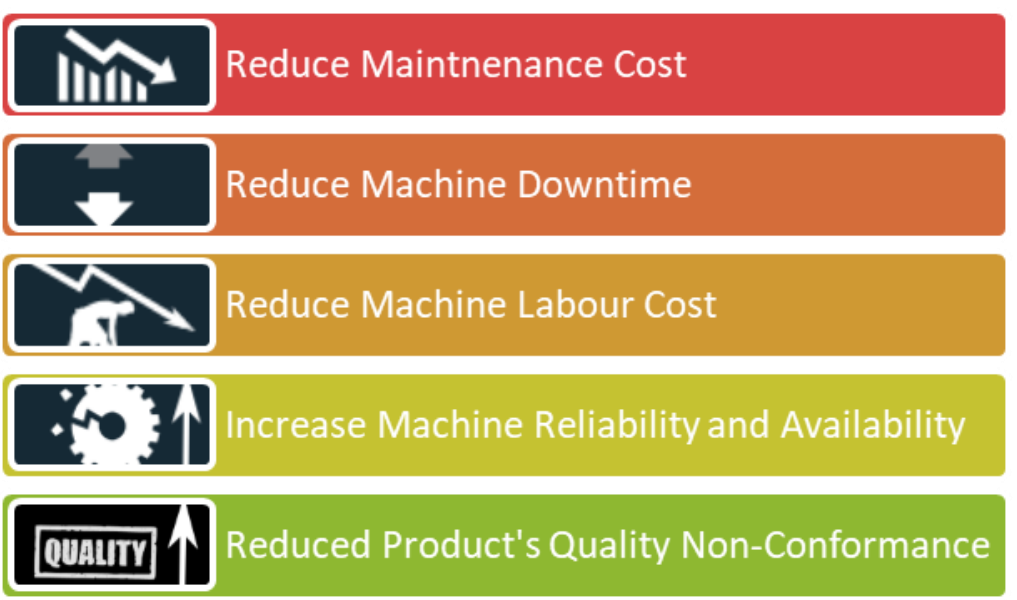

Fig. 8 Motives for Predictive Maintenance Adoption

\subsection{Overall Impact of Current Maintenance Strategy for CNC Machine Tools}

A Pareto Chart was generated to establish a relationship between the existing maintenance strategy of these organisations and its impact on the overall organisation's cost, quality, safety and productivity. Based on the Pareto principle, which states $20 \%$ of problems drive the remaining $80 \%$ of problems; 
therefore, by addressing the accumulated majority (vital few) on the left hand side, the results will provide direct and indirect impacts to resolve the accumulated minority (trivial many) on the right hand side [51,52]. Figure 9 presents participants' responses on probable issues associated with their current maintenance strategy.

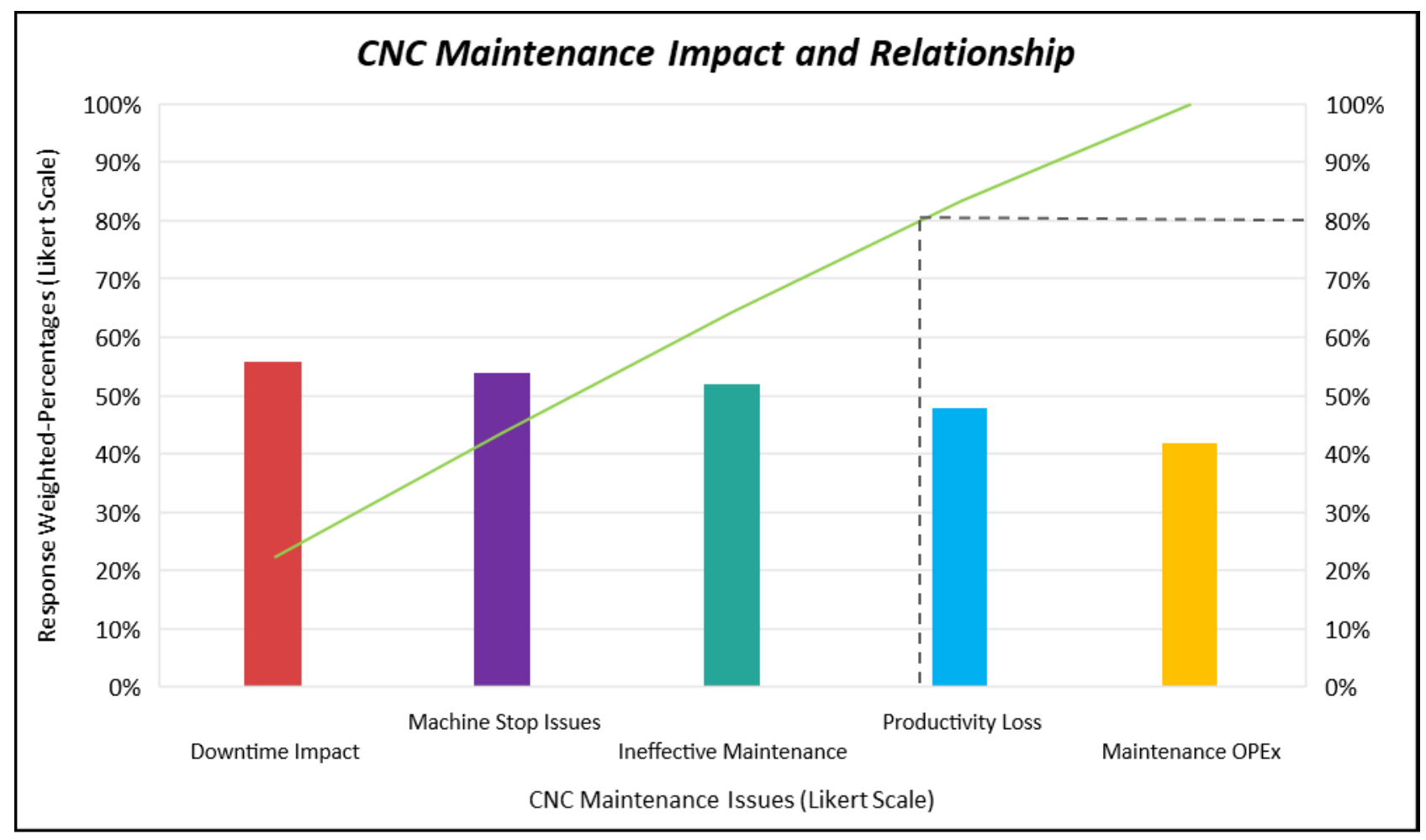

Fig. 9 Pareto Chart of Current Maintenance Impact and Relationship

In order of priorities, first the 'downtime impact' was the highest concern especially to SMEs whenever the machines are not operating due to low machine effectiveness. Second was 'machine stop issues' as another significant concern, this relates to the Mean Time Between Failures (MTBF). Third was the 'ineffective maintenance', which makes a logical connection with the "Swiss-Cheese" model that the loopholes in the existing maintenance strategy lead to increased probability of downtime and machine stoppage. As mentioned earlier, one can appreciate addressing these three priority issues can provide gains in reduced lost productivity, MT operating expenditure ("OPEx”) and ultimately gaining Life Cycle value from the MT.

\subsection{Development of Parametric Cost Model}

The parametric cost model results are presented in this section for key parameters that were deemed critical maintenance cost drivers, with the intent to establish potential relationships. Just like any parametric model, the major limitation is the potential for over simplification of intrinsic influencing factors, as well as it being at risk of inapplicability when extrapolated beyond the sample range. Nevertheless, this study seeks to initiate research into this area and keep it simple for SME respondents to interpret and relate to beyond complexities and avoid the challenges of adaptive implementation as stated by Moeuf et al. [53]. 


\subsubsection{Key Assumptions for Parametric Modelling}

There was the need to make certain assumptions to rationalise the data responses for the modelling process. The model's major parameters considered are: Machine Data Extraction (MDE), Machine Tool Quantity (MTQ) and Machine Failure Rate (MFR)

\section{Modelling Hypotheses}

This section focusses on explanatorily investigating the maintenance cost drivers of SME's using CNC MT. The above parameters' (MDE, MTQ, MFR) relationship with Machine Operating Cost (MOC), Machine Maintenance Cost $(M M C)$, Machine Lost Productivity Cost $(M L C)$, Machine Downtime Cost $(M D C)$ and Machine Overall Effectiveness (MOE) were investigated as shown in Equation (1) to Equation (5). The formulated null hypothesis was input variables $(\operatorname{Inp} V)$ insignificantly correlate and predict output variables $(O t p V)$ in a simple parametric linear relationship (cost model); and the alternative hypothesis was InpV significantly correlate and predict OtpV in a simple parametric cost model.

$$
\begin{gathered}
M M C \stackrel{\text { yields }}{\longrightarrow} f(M D E, M F R, M T Q) \\
M O C \stackrel{\text { yields }}{\longrightarrow} f(M M C) \\
M L C \stackrel{\text { yields }}{\longrightarrow} f(M M C) \\
M D C \stackrel{\text { yields }}{\longrightarrow} f(M M C) \\
M O E \stackrel{\text { yields }}{\longrightarrow} f(M F R)
\end{gathered}
$$

Key assumptions were made for the parametric modelling of the survey results, and the following parameter are captured:

- Machine Tool Quantity (MTQ) assumed median value of each group's range.

- Machine Operating Rate (MOR) assumed machines operated continuously per shift.

- Machine Failure Rate (MFR) assumed one failure possibility for each specified range.

- Machine Maintenance Cost $(M M C)$ assumed cost in units of tens-of-thousands $\left(1 \times 10^{4}\right)$.

- Machine Maintenance Type (MMT) assumed numeric values for each maintenance type.

- Machine Repair Ownership (MRO) assumed numeric values for each ownership type.

- Machine Data Extraction (MDE) assumed numeric values for data collection scenario.

- Statistical Testing assumed data from individual each group as unpaired and unrelated.

\subsubsection{Bivariate Relationships in Parametric Models}

The basic mathematical linear equation was used to correlate data in a simple and logical manner, thus in Section 4.4, Equation 6 to Equation 10 were derived through investigation of input variables (InpV) 
theoretical and statistical significance in predicting output variables $(O t p V)$ through linear regression analysis which was performed in SPSS and supported with graphs from MS Excel. This section focuses on the MMC and its impact on other MT performance measure deemed relevant to management [30]. The plotted relationships between individual parameters and MMC are shown in Figure 10 to Figure 14, and discussed hereafter.

In Figure 10, the plotted relationship between MMC and MTQ revealed an inversely proportional relationship; thus, as MTQ increases, MMC decreases. Although one may expect more MT means more maintenance costs, this relationship suggests an indication of economy of scale and scope.

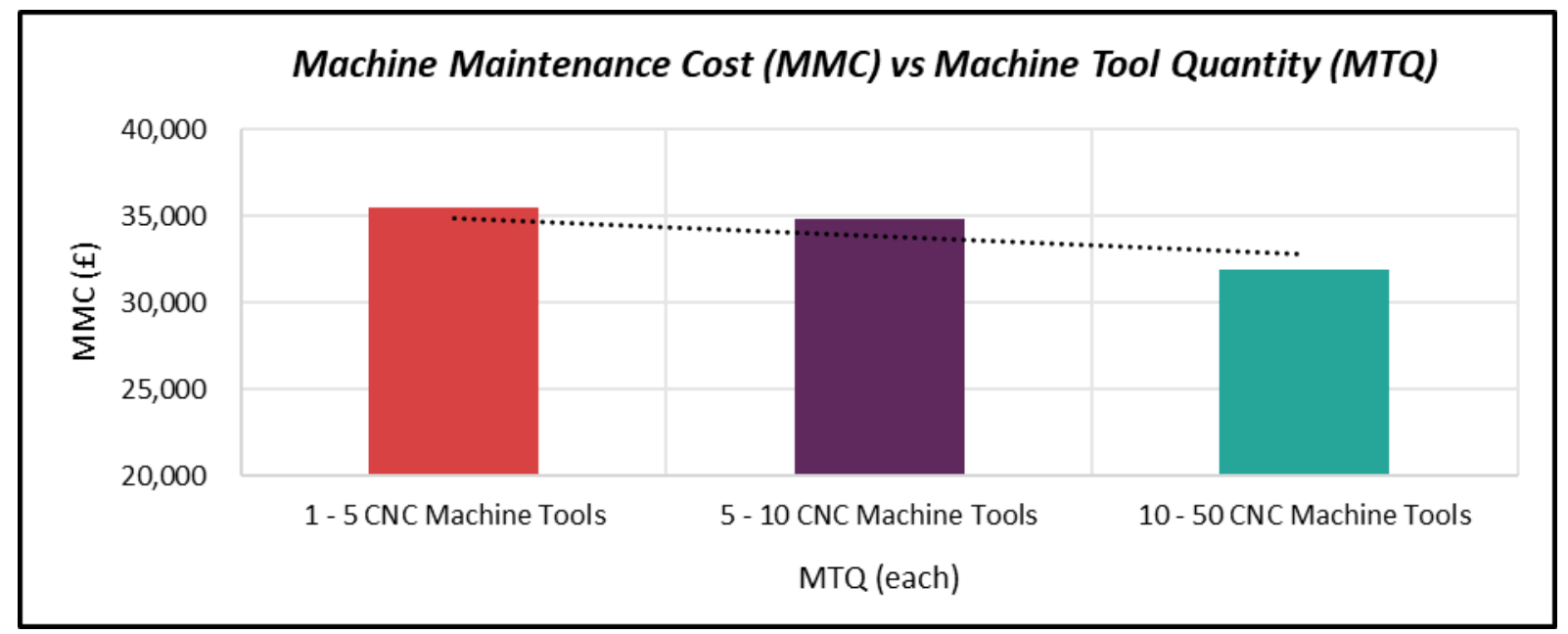

Fig. 10 MMC vs MTQ

In Figure 11, the plotted relationship between MMC and MFR revealed a directly proportional relationship; thus, as MFR increases, MMC increases. Authors infer this supports the logic of more failure means more maintenance activities and costs.

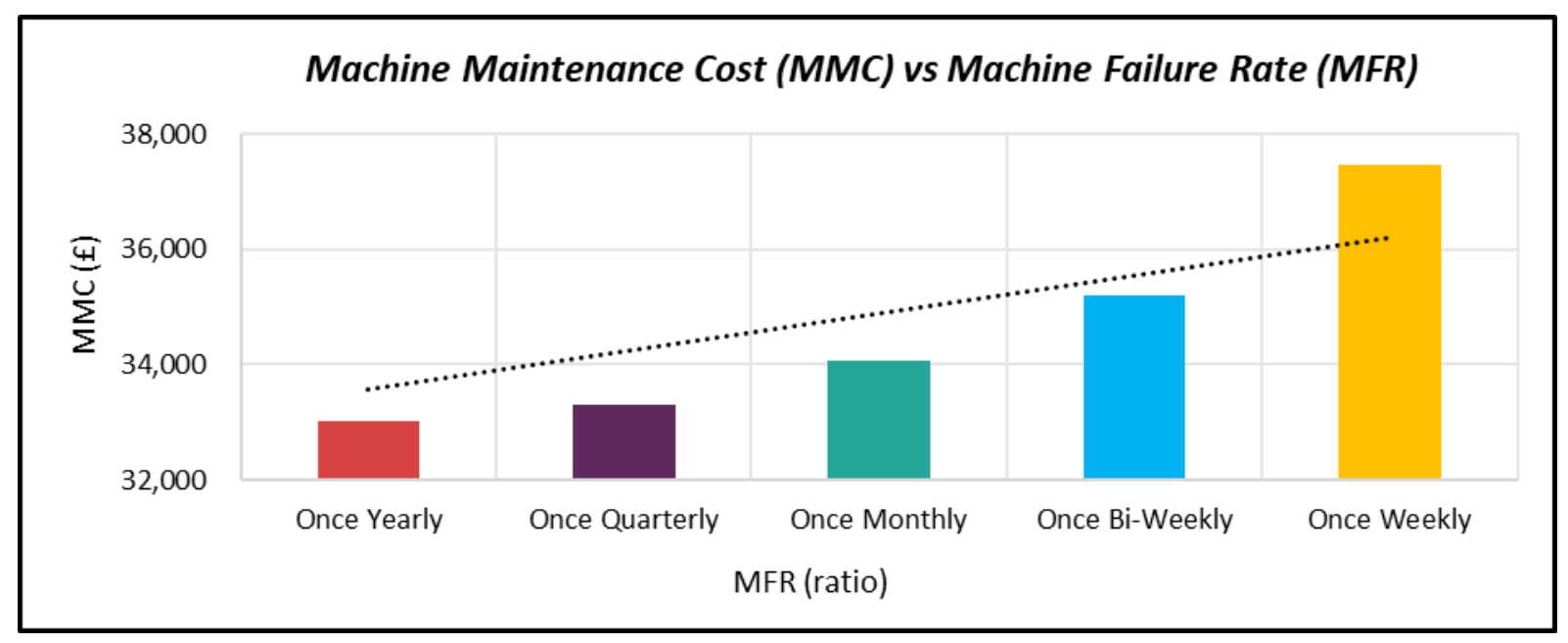

Fig. 11 MMC vs MFR

In Figure 12, the plotted relationship between MMC and MDE revealed a directly proportional relationship; thus, MMC increases as MDE increases on the scale 1-5 for MT performance data and condition monitoring (where 1 represents no participation, and 5 represents full participation). One may infer this cost relations as evidence of potential additional costs associated with acquiring and maintaining digital infrastructure for PdM; however, the gains are with reduced lost productivity and unnecessary maintenance due to active MT active performance and condition monitoring. 


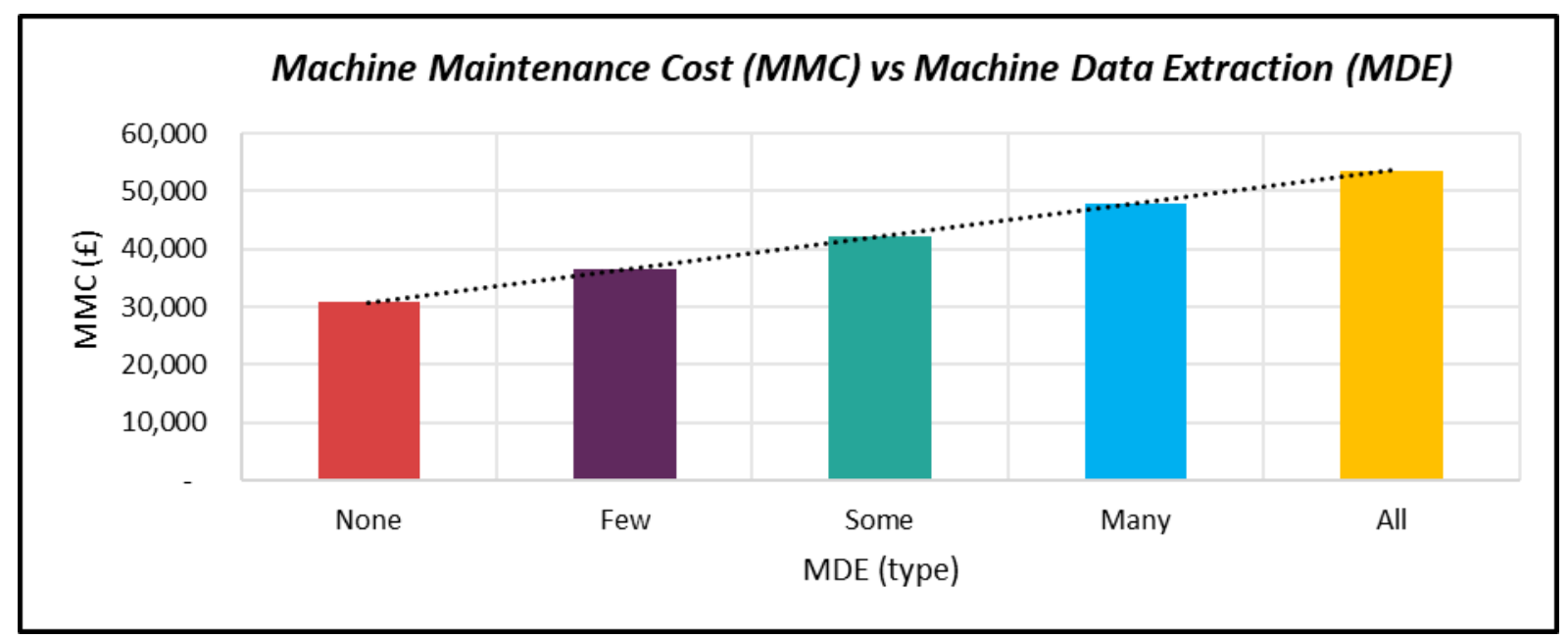

Fig. 12 MMC vs MDE

In Figure 13, the plotted relationship between MMC and MMT revealed an inversely proportional relationship; thus, as MMT changes from "PdM", through "CM" into "PM", MMC decreases. Although $\mathrm{PdM}$ comes with additional costs and $\mathrm{PM} / \mathrm{CM}$ are the least costly strategies; there are more cost drivers of MMC which PdM can influence for reduction. Furthermore, the costly impact of CM due to unplanned failure, while PM is deemed less costly due to its progressive development is clearer.

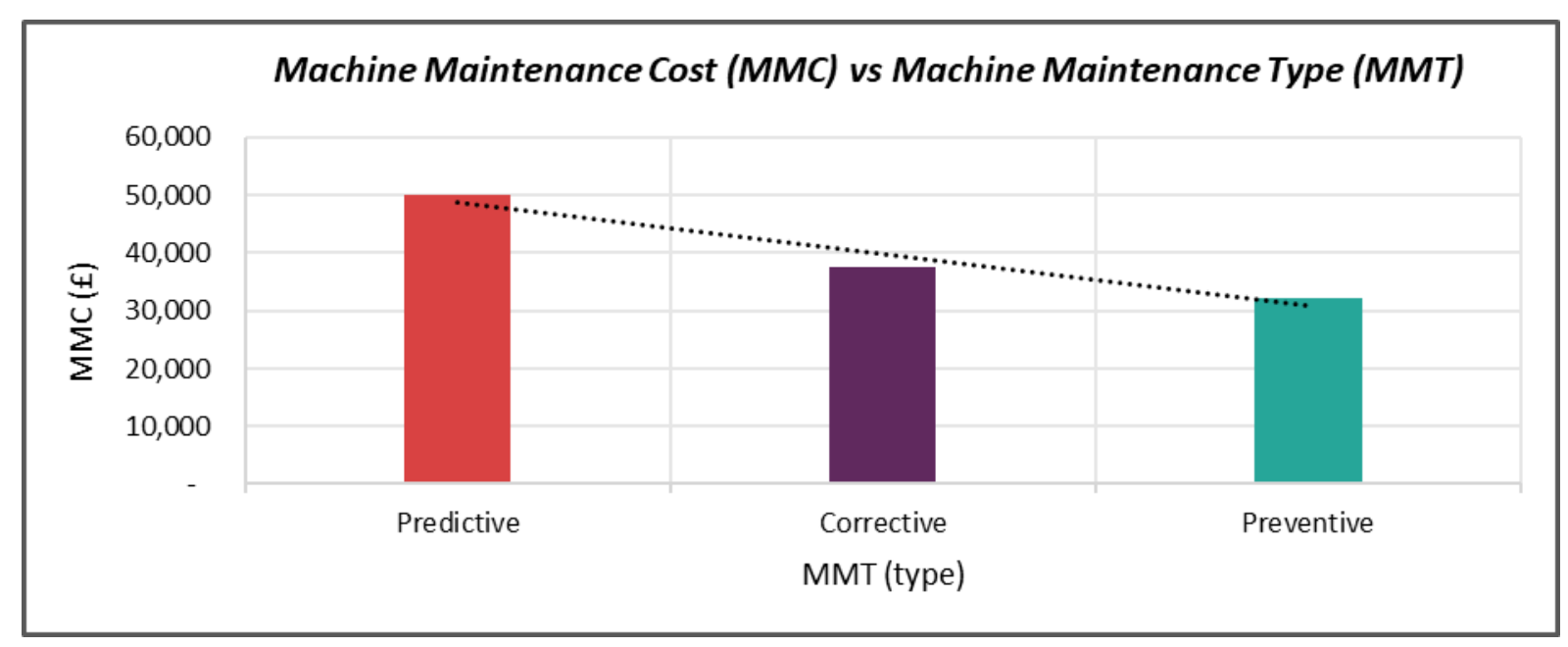

Fig. 13 MMC vs MMT

In Figure 14, the plotted relationship between MMC and MRO revealed a directly proportional relationship; thus, as MRO changed from Leased into Owned, MMC increases. One may infer this as evidence for potential justification that maintenance impact is felt more by organisations owning the MT thus taking on the full LCC, as compared to those leasing the MT and takes on minimal LCC. 


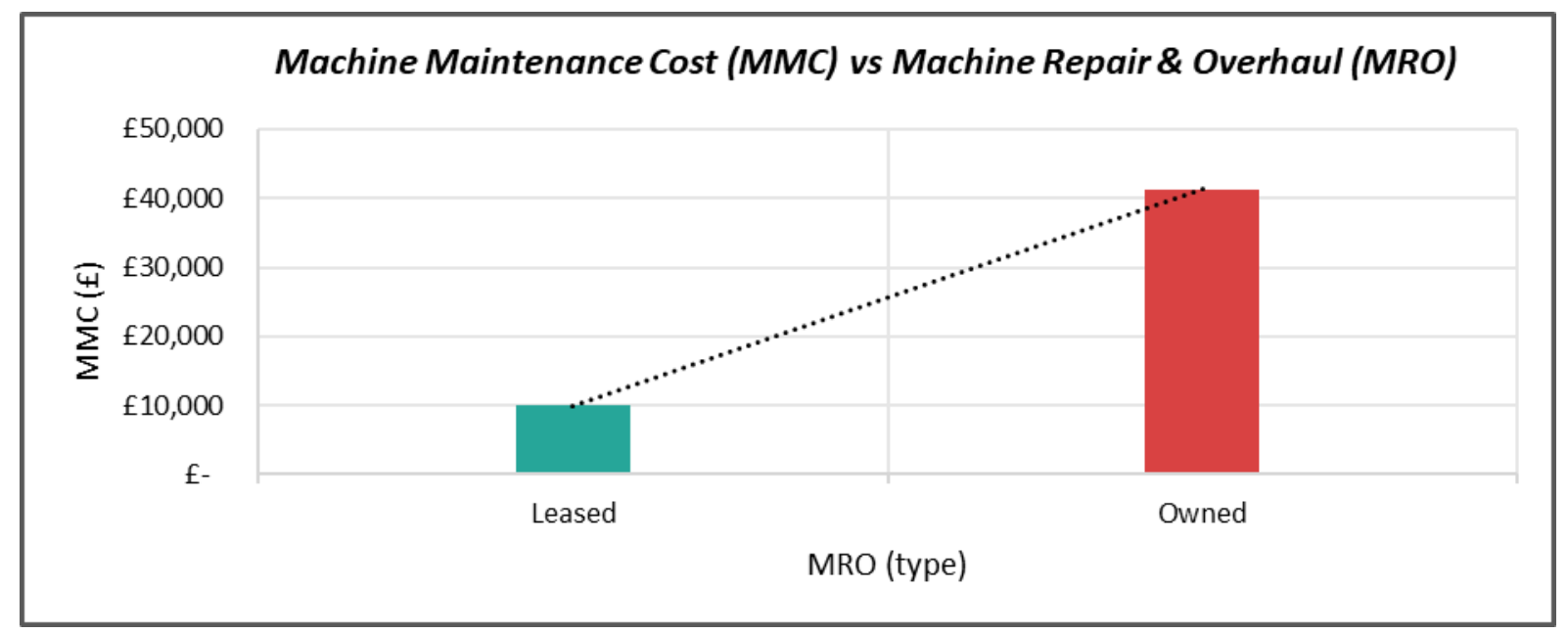

Fig. 14 MMC vs MRO

In summary, the relationships demonstrated simple bivariate relationships between MMC and its predictors (MDE, MFR, MTQ); and this approach was used for all the other output parameters that relate to MMC. A number of these parameters seem to form weak relationships with MMC, in terms of the coefficient of determination $\left(R^{2}\right)$ values with the exemption of MRO's dummy variables. Therefore, all relationships were investigated through exploratory statistical methods to check the degree of accuracy in predicting MMC and potential cross-relationship beyond $\mathrm{MMC}$, as detailed in the next section [50].

\subsection{Statistical Confirmation on Parametric Relationships Validity}

This section addresses statistical relationships between parameters. The selected of significance level ( $\alpha$-level) was 0.20 with $80 \%$ power confidence and $5 \%$ error margin for the 21 responses (deemed as population size); thus the evaluated applicable sample size was 19 responses (verified via the online survey platform). The adapted population and sample size were due to limited participation and data accessibility within the research constraints; nevertheless, the selected and achieved statistical power confidence, significance level and sample size were in accordance to recommendations by Vishwakarma [60] and Kim [54]. Correlation and linear regression were performed to investigate significant predictors of other parameters; thus, evaluating the modelling hypothesis using multivariate regression in SPSS and Microsoft Excel.

Equation 6 to Equation 10 show linear equations generated from the multivariate regression and consequently, used for the cost model. Since MMC was the main output, it is examined briefly in this section. The Equation 6 shows that all coefficients are positive except MTQ, which seems to confirm that the logical relationship of DV being directly proportional to InpV and increased MMC. Alternatively, the negative coefficient of MTQ, demonstrates an indirectly proportional relationship between MCC; therefore, it reduces MMC. Secondly, the absolute values of each predictor's (InpV) coefficient demonstrate MFR, MDE and MTQ, respectively, contributes significantly towards the MMC. The intercept shows that the MCC begins above zero (0), which indicates that there are other elements of MMC, aside from these InpVs. The MMC prediction iteration for linear relationships with other parameters implication are briefly shown and discussed below. 


$$
\begin{gathered}
M M C=17719+8094 M D E+173052 M F R-526 M T Q \\
M O C=29516+1.4 M M C \\
M L C=753+0.8 M M C \\
M D C=1021+0.8 M M C \\
M O E=0.69-1.99 M F R
\end{gathered}
$$

Although MRO demonstrated a stronger $\mathrm{R}^{2}$ value when related to MMC, it was exempted from MMC's final predictor variable list because it served as an exploratory (dummy) variable to understand the qualitative impact of MT ownership within the dataset; thus avoiding any sign of bias that Kim [54] and Figueiredo Filho et al. [55] cautioned researchers on blindly accepting statistical significance.

One may be curious on how MMT relates to MMC. However, this led to an insignificant results from both the correlation and regression analysis. When the MRO is inserted into the predictor variable pool, it shows itself as the only significant value and pushes other theoretical values beyond the $\alpha$-value. When examined closely, it was clear that the cluster of MRO responses were owned MT rather than leased; thus the exploratory (dummy) variable MRO confirmed the significant difference between MT ownership by revealing that SMEs who owned the MTs felt the impact of MMC more when MRO was incorporated into the regression model [56,57].

The InpVs, MDE, MTQ and MFR, did not individually provide the strongest account on variations, however, they performed better when combined, both statistically and theoretically towards MMC's prediction; thus, these InpVs were retained [55].

Additionally in an attempt to verify the model's reliability on unseen small-n data; the 70-30 data splitting rule was applied. Acquired data was entered by participants without a deliberate sequence, thus enabling the data to be randomly grouped into two dataset: training and test sets. The training datasets were used to develop a regression model and the test dataset were used for the model's validation. The output for all cases were cross-validated by comparing the absolute error in the predicted outputs of both the training and test outputs with that of the benchmark model; sample results are reported in Table 3.

Table 3: Cross-Validation Datasets Model Outputs (Predicted Values)

\begin{tabular}{|c|c|c|}
\hline Trial\# & $<\mathbf{1 0 \%}$ dataset variance & $<\mathbf{2 0 \%}$ dataset variance \\
\hline $\mathbf{1}(\mathbf{1 4}$ train, 5 test) & $\begin{array}{c}4 \text { entries of test dataset } \\
\text { (67\% of test dataset) }\end{array}$ & $\begin{array}{c}5 \text { entries of test dataset } \\
\text { (83\% of test dataset) }\end{array}$ \\
\hline $\mathbf{2}$ (15 train, 4 test) & $\begin{array}{c}3 \text { entries of test dataset } \\
(60 \% \text { of test dataset })\end{array}$ & $\begin{array}{c}4 \text { entries of test dataset } \\
(80 \% \text { of test dataset })\end{array}$ \\
\hline
\end{tabular}

Results in both cases reveal that over $60 \%$ of the test datasets had a $<10 \%$ variance $(90 \%$ accuracy) from the benchmark model's data, while over $80 \%$ of the test data had $<20 \%$ variance ( $80 \%$ accuracy) 
from the benchmark model's data. This aided in affirming a relationship validity at the $80 \%$ power confidence level set for the parametric model and equally validate the model's accuracy at $80 \%$.

\subsubsection{Parametric Cost Model Output}

This section presents trends established with the theoretically and statistically significant predictors of MMC from the developed PdM Cost Model. Table 4 indicates an output on the expected cost savings when comparing MMT, MTQ, MFR and MDE with MMC. Where MTQ varied while all other variables remained fixed over 1-50 CNC MTs. The trend in Table 4 generally predicts cost savings for operating more MT with PdM and PM. While CM predicts no savings, PM cost savings begins at $£ 773$ for one MT and increases to $£ 22,686$ for $50 \mathrm{MT}$, and PdM cost savings begins at $£ 22,804$ for one MT and increases to $£ 48,585$ for $50 \mathrm{MT}$. These predicted cost saving results are derived from primary data modelling in concordance with literature and were not values obtained directly from on-site observations.

Table 4 Maintenance Cost Savings Mapping Over 1-50 CNC MTs

\begin{tabular}{|c|c|c|c|}
$\begin{array}{c}\text { Maintenance } \\
\text { Strategy } \\
(\text { MMT) }\end{array}$ & $\begin{array}{c}\text { Failure } \\
\text { Rate } \\
(\text { MFR) }\end{array}$ & $\begin{array}{c}\text { Data } \\
\text { Collection } \\
(\text { MDE) }\end{array}$ & $\begin{array}{c}\text { Predicted Amount of } \\
\text { Estimated Savings } \\
(\mathfrak{(})\end{array}$ \\
\hline Corrective Maintenance $(\boldsymbol{C M})$ & Weekly & None & $£ 0$ \\
\hline Preventive Maintenance $(\boldsymbol{P M})$ & Monthly & Some & $£ 773-£ 22,686$ \\
\hline Predictive Maintenance $(\boldsymbol{P d M})$ & Yearly & All & $£ 22,804-£ 48,585$ \\
\hline
\end{tabular}

Figure 15 and Figure 16 show the cost model's output for MMC, MOC, MLC and MDC of both maintenance strategies ( $P M$ and $P d M)$ to support understanding of the trend with increasing operation of MTs. Figure 15 shows a decreasing trend for MOC and its components, the cost contributors show marginal cost savings; thus, eventually resulting in MOC entering savings at 45 MTs when using PM. Figure 16 shows a decreasing trend for MOC and its components too. However, all the cost contributors show cost savings from one MT onwards, thus resulting in significant MOC savings when applying PdM. 


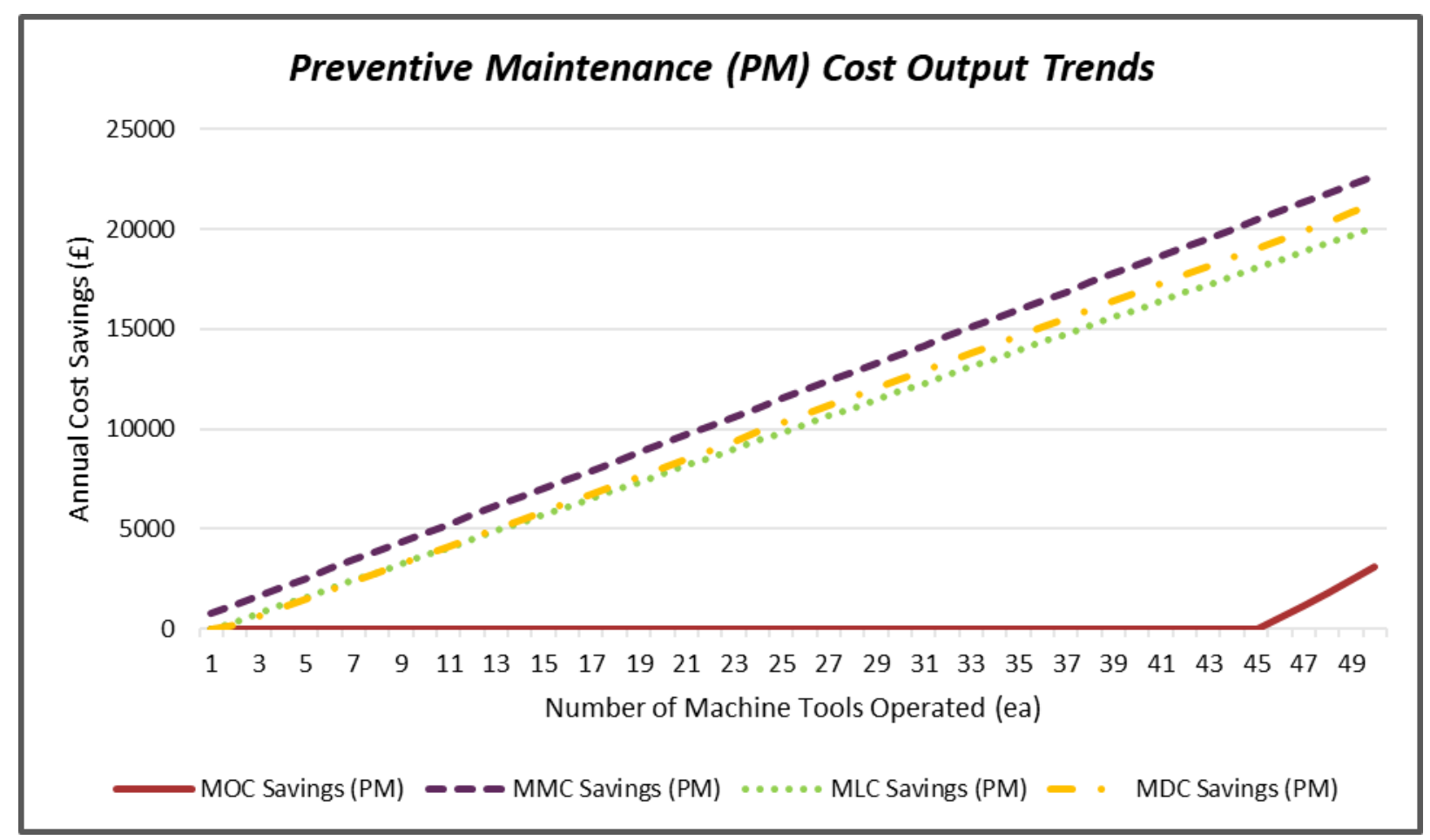

Fig. 15 Cost Model Output: MMT=PM, MDE=Some, MFR=Month

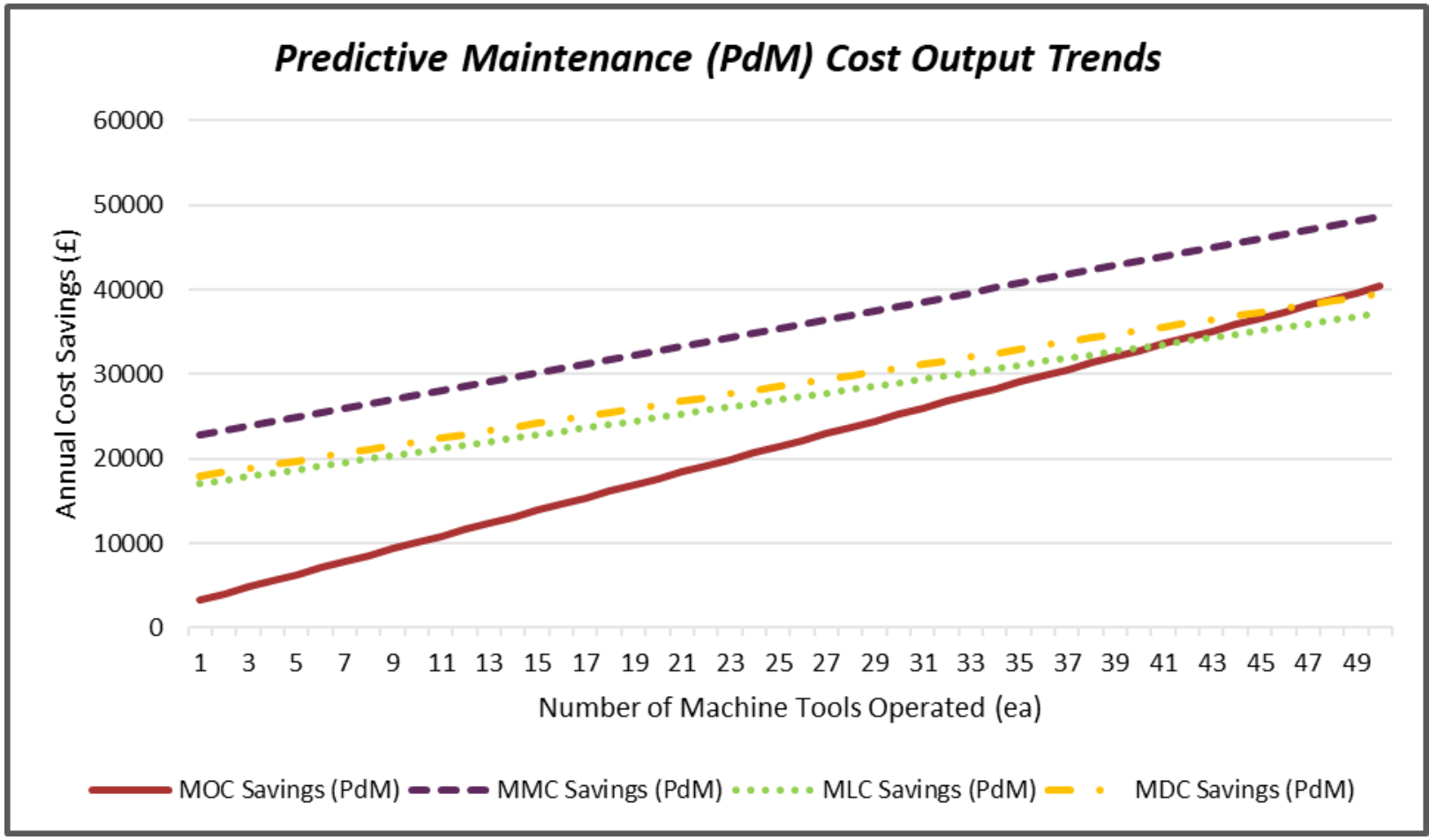

Fig. 16 Cost Model Output: MMT=PdM, MDE=All, MFR=Yearly

The parametric cost model outputs demonstrated a relationship between MOC, MMC, MLC and MDC with their predictors MDE, MTQ, MFR and MMT. The next section discussed the data analysis results and reflects on literature in the context of this paper's hypotheses $(\mathrm{H} 1-\mathrm{H} 3)$. 


\section{Discussion}

In Section 2, both academic and industry related literature were reviewed on existing trends in maintenance strategies, MT evolution, maintenance's impact on their LCC and how these literatures are significant to SMEs. In Section 4, the results of primary data and secondary data assessments established a meaningful trend between MT maintenance strategies and their estimated annual maintenance cost contribution to the MT's LCC; the section identified potential cost savings trends when PdM is fully applied factory wide and over a larger pool of MTs.

\subsection{Hypothesis (H1)}

Reviewed literature revealed PdM as "nothing-new"; however, new technologies and frameworks have augmented PdM's potential to migrate into Industry 4.0 [17]. Survey responses confirmed existence of CNC MTs equipped with data collection technologies within SME CNC machine shops. More recent literature argues that the PdM adapts from PM, which provides a rudimentary perspective on maintenance as a value-adding activity. Therefore, with survey results revealing PM as the predominant SME maintenance strategy, it sets the path for suitable PdM adaptation. Lastly, industry case studies of implementing $\mathrm{PdM}$ for $\mathrm{CNC}$ machine shops were confirmed through survey results, with existing evidence of PdM application for SME CNC machine shops; thus affirming PdM's suitability for SME CNC machine shops in "Industry 4.0 ".

\subsection{Hypothesis (H2)}

Initial analysis demonstrated Machine Maintenance Cost $(M M C)$ as inversely proportional to Machine Maintenance Type (MMT); thus suggesting PdM is more expensive than PM and CM. However, literature review demonstrated significant cost reduction when migrating from traditional maintenance (PM or CM) to PdM (see Figure 3). The PdM's relative high costs can be associated with initial implementation (see Table 2). However, empirical data analysis revealed PdM as the most cost-effective maintenance strategy (see Figure 10). Correlation and regression analysis confirmed Machine Data Extraction (MDE), Machine Failure Rate (MFR) and Machine Tool Quantity (MTQ) as MMC's significant predictors. MMC's predictor coefficients $(B)$ demonstrated MDE as the better alternative. However, MFR was the most influential cost driver because each unit decrease of MFR resulted in $£ 173,052$ reduction in MMC per year. Additionally, each unit increase in MDE resulted in $£ 8,094$ increase in MMC, while each unit increase in MTQ resulted in $£ 526$ decrease of MMC. Maintaining MDE at least capacity results in approximately $33 \%$ of its influence on the cost driving potential of MFR; however, increasing MDE to full capacity results in approximately $85 \%$ influence on the cost driving potential of MFR. As PdM seeks to significantly reduce MFR, it will reduce MMC and the impact of MDE's cost significantly (see Equation 6). Results in Table 5 shows significant evidence that InpVs (MFR, $M D E, M T Q)$ significantly predict OtpV $(M M C)$. 
Table 5 Machine Maintenance Cost Model Descriptive Statistics

\begin{tabular}{|r|c|c|c|c|}
\hline & MMC & MFR & MDE & MTQ \\
\hline Mean & $£ 34736.84$ & 0.06 & 1.68 & 12.37 \\
\hline Standard Deviation & $£ 18064.21$ & 0.05 & 1.20 & 12.41 \\
\hline Median & $£ 30000.00$ & 0.04 & 1 & 7 \\
\hline \multirow{2}{*}{ Model Summary } & \multicolumn{4}{|c|}{$M M C \stackrel{\text { yields }}{\longrightarrow} f(3,15)=2.14, \mathrm{p}=0.14$} \\
\cline { 2 - 5 } & \multicolumn{4}{c}{. }
\end{tabular}

The model's fit summary metrics, $\mathrm{R}^{2}$ and adjusted $\mathrm{R}^{2}$ shows $30 \%$ to? $16 \%$ of the variance in MMC was accounted for by its linear relationship with its predictors (MFR, MDE and MTQ). A number of literature indicated PdM reduces MFR (see Table 1), hence resulting in MMC reduction. Adopting caution by Figueiredo Filho et al. [55] on blindly following statistical significance norms of $\mathrm{p} \leq 0.05$; this MMC model was deemed significant to account for $\alpha$-level of 0.15 and $85 \%$ confidence level; which was lower than the initially selected $\alpha$-level and confidence level for analysis. Apart from the small sample size, both statistical and theoretical evidence deem this model's outputs as significant because the results ranges were compliant with the research investigations in reviewed literature; thus, affirming PdM as cost effective for SME CNC machine shops. This partially confirms hypothesis (H2) as it demonstrates PdM might be costly for a single SME with small MTQ (1-5), but is cost effective as MTQ increases.

\subsection{Hypothesis (H3)}

Considering the benefit-cost ratio (value) definition, value is improved by either reducing costs, increasing benefits or both. A number of literature suggested benefits of PdM which include reduced maintenance, lost productivity and downtime costs. Additionally, PdM improves machine availability, reliability and Machine Overall Effectiveness (MOE) by reducing MFR (see Table 1). Analysis results buttress this claim in literature by identifying MFR as the major maintenance cost and performance driver, though it seemed to have a weaker correlation; therefore, incorporating MFR from a theoretical perspective in relation to MMC, where the Type II error was avoided [54]. The relationship between MFR and MOE were inversely proportional; thus, as MFR reduced, MOE increased. Also, the relationship between MFR and MMC were directly proportional; thus, as MFR reduced, MMC reduced. These significant relationships established through data analysis suggest MFR is an influencing factor which can result in value creation when tackled properly. The PdM seeks to reduce MFR by monitoring and predicting imminent failure, thus MMC is reduced while improving productive uptime and MOE. This significantly aligns with tangible value creation for SME CNC machine shops, thus PdM supports value by reducing cost and increasing R\&M and OEE metrics [19].

\subsection{Additional Comments}

The financial cost model are consistent with most of the literature and case studies on PdM adoption benefits and add additional perspective in the case of CNC SMEs. Additionally, MMC's high correlation with Machine Repairs and Overhauls (MRO) demonstrated some validation on the assumption that the SMEs who own their MTs will be highly affected by their maintenance costs. The SMEs seem to be 
predominantly implementing PM. However, their breakdown frequency of one month or less accounts for about $70 \%$ of breakdowns. This underlines the existing challenges with effective maintenance as argued by Marais and Saleh [58] and Galar et al. [19]; thus, providing a sound justification to migrate towards PdM to reduce MFR. The results suggest evidence on SMEs being impacted by imperfect PM and provide some understanding on their high maintenance costs. From the perspective of readiness for Industry 4.0, it is evident that most of the SME's CNC MTs are unequipped with data collection sensors and are prone to high MFR as recorded in approximately $68 \%$ of responses.

\subsection{Academic and Practical Comparison}

The results evidently enable one to appreciate PdM's contribution towards reducing productivity loss and operating expenditure ("OPEx") by addressing downtime impact, machine stop issues, and ineffective maintenance. These are issues from industry mentioned in the several literatures, presenting a sound response to hypothesis (H2); nevertheless, as Equation 6 demonstrates a starting intercept point of $£ 17,719$. This shows PdM requires additional overhead costs for both physical and data systems as well as information security. Although comparing the means of PdM, PM and CM suggest that PdM is more expensive than the others, considering the significant contribution of breakdown frequency on maintenance cost concludes that $\mathrm{PdM}$ is deemed to be the best solution among all three maintenance techniques as it will predict imminent failures and eliminate unrequired scheduled maintenance based on Machine Tool (MT) condition monitoring. It was inferred that the difference in mean costs was due to the lack of adequate data of PdM for MT by SMEs (14.3\% of total MMT). Major feedback from participants expressed positive value of the cost estimation dashboard's assistance in making informative maintenance decisions; while, minor feedback expressed need for orientation on operating the dashboard.

This study's output adds insight into the essence of SMEs readiness for Industry 4.0 migration. As future of manufacturing is trending and new technologies are supporting PdM and Cyber-Physical Maintenance (CPM), this study's novelty contribute towards both academic and industrial partnership with SMEs pooling together to optimise their CNC MT maintenance costs through the recommended system architecture proposed below in Figure 17. 


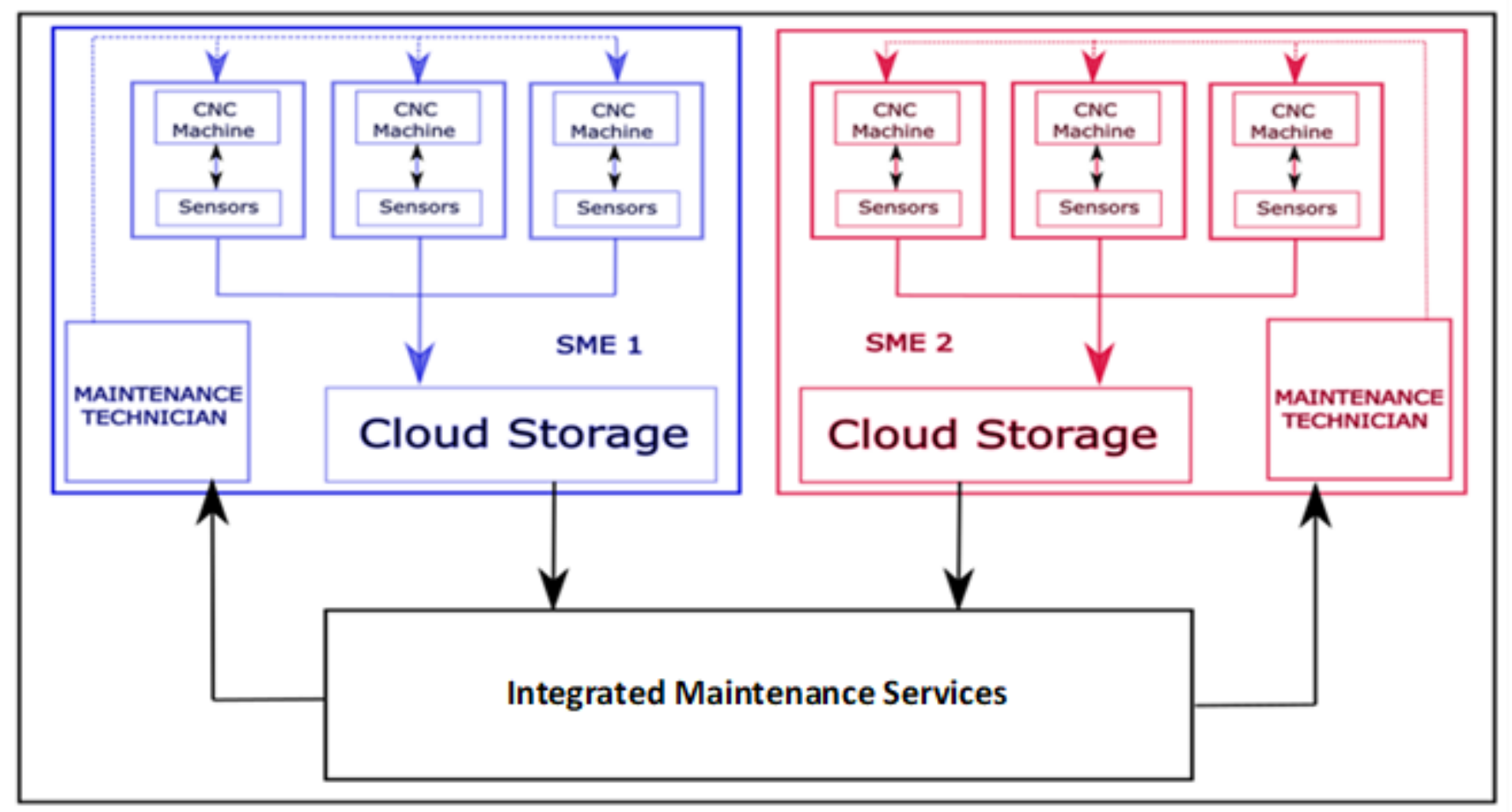

Fig. 17 Proposed DNC PdM System Architecture for SME Pooling

As demonstrated from the inverse cost relationship with quantity of machines, and through existing DNC protocols discussed in literature review, it is proposed that the networked CNC MTs in organisations pool their resources through a central data collection and maintenance service; thus building upon the shared maintenance database capabilities concepts by Kans and Ingwald [32] to adapt MT maintenance capabilities and decisions further towards IR4.0. The SMEs will benefit not only from economy of scale and scope, but also from the shared intelligence of predicting failure, scheduling maintenance, and securely transferring capabilities to other members on the network. The network will support reducing lost productivity, downtime and maintenance costs and ultimately operating costs towards extending the useful life of CNC MT and reducing its LCC through PdM.

As part of the research, a Power BI Dashboard was developed and can be publicly accessed at: https://bit.ly/2w7IoZd

\section{Conclusion and Future Research}

This study originated from an intersection of industrial transformation, $M T$ maintenance, $L C C$ and their overall impact on a SME's readiness for Industry 4.0. The study sought to investigate SME CNC machine shops' readiness to adopt and sustain PdM within Industry 4.0 and makes the following contributions below.

Identifying PdMs suitability for SME CNC machine shops in "Industry 4.0": this is evident from the statistical data results and analysis on survey responses, showing that some SMEs are using PdM; however, majority are using PM and CM. The results supported with secondary data suggest that predictive maintenance can be implemented by SMEs. Proposing a cost effective PdM DNC system architecture for SME CNC machine shops: this is evident from a combination of literature review from 
industry and academia that was used to verify the analysed survey results to establish a cost model. The cost model estimates PdM as the most cost-effective strategy for SMEs with predicted cost savings ranging from $£ 22,804-£ 48,585$ compared to $P M$ which ranged from $£ 773-£ 22,686$; with no savings for $\mathrm{CM}$. The modelled range was from 1-50 CNC MTs; therefore, providing significance to the proposed DNC PdM system architecture that allows SMEs to pool together. Nevertheless, some of the limiting issues of small sample size resulted in 16\%-30\% account for variance in maintenance cost prediction by its predictors; thus, an increase in sample size and further multivariate analysis could have resulted in improved $\mathrm{R}^{2}$ and adjusted $\mathrm{R}^{2}$ values, and ultimately improved confidence power. Additionally, the large data may be analysed from multiple perspectives that support statistical robustness testing and validation techniques. Furthermore, this exploratory venture affirmed PdM's additional tangible value creation for SME CNC machine shops: the demonstrated inversely proportional relationship between failure rate and maintenance, downtime and lost productivity cost, as well as machine overall availability and effectiveness as discussed; thus, resulting in significant and tangible value creation for the SME. Nevertheless authors acknowledge the model's predicted output require a next stage of further participatory verification and exploratory adaptation as deemed relevant to selected cases of SMEs providing actual observed data after implementing the proposed system architecture.

A limitation to this research finding is its focus area on UK's criterion on SME definitions; nevertheless these have a scalable adaptability to the European region due to close similarities on SME definition criteria. Furthermore the focal predictors were MTQ, MFR and MDE, which are usual maintenance data that are tracked by most large companies thus facilitating the opportunity to address scalability by the theory proposed. Nevertheless, since MMC entails several influencing conditions and each MDE practice or package may differ from company to company, there remains a potential limitation on immediate transferability without tailoring the model specifically for their operation. Authors consider the model's principles are consistent with literature, thus in theory the model serves as a reference point for PdM decision making at different CNC companies size both within and beyond UK. In order to successfully adapt the model to a setting beyond the purpose authors specify for, a larger company or one beyond the UK will have to assess their MFR and MDE levels; then convert them onto a numeric scale 0-1 and 1-5 respectively as designed. Additionally the MTQ margin within 1-50 will require direct plug in of the MTQ; however, beyond 50+ MTQ; there will be a requirement for the organisation to extrapolate with parameters from within the PdM Cost Model's range. Finally with the issue of currency conversion from GBP to any other currency, the user beyond UK will require a conversion rate that is equivalent to that of 2017-2018.

Despite the strong advocacy for "Industry 4.0" of MTs; it must be cautioned that there are several concerns or questions beyond the scope of this study that must be addressed on readiness to adapt DNCs maintenance systems in terms of information security shown in Table 6. These are areas worthwhile addressing in further research to assure the readiness of SME CNC machine shops migration into Industry 
4.0. It is therefore recommended that further research in this area be continued with larger data sample sizes and improved statistical power. Additionally, issues associated with information security and data protection for the proposed system is equally recommended for consideration by future researchers. Finally, extended literacy of Industry 4.0 from the perspective of SMEs is encouraged since the report by Wright [59] reveals SMEs are great contributors to Gross Domestic Products (GDP) with 2.0tn annual revenue that represented $52 \%$ of UK's private sector; thus should not be excluded from Industry 4.0 migrations.

Table 6: Cyber Security Concern Areas Questions \& Descriptions

\begin{tabular}{|l|l|}
\hline Concern Area & Concern Questions/Descriptions \\
\hline Data collection and storage strategies & $\begin{array}{l}\text { What gets measured and who or where does it get stored, be } \\
\text { it internally or externally? }\end{array}$ \\
\hline Network infrastructure service plans & $\begin{array}{l}\text { Is the network infrastructure contract setup for support or } \\
\text { maintenance by an external company or everything } \\
\text { managed in house? }\end{array}$ \\
\hline Data protection plans & $\begin{array}{l}\text { Level of privacy on sensitive data collected, 3rd party } \\
\text { company's privileges to the company's machine tool data } \\
\text { e.g. tolerance, machining time, down time, etc.), how does } \\
\text { unused data get destroys? Are Antivirus, Malware or } \\
\text { Firewalls that block out hackers or competitors? }\end{array}$ \\
\hline Access Control & $\begin{array}{l}\text { Who has access to this data and what level of information } \\
\text { can be accessed, which other network infrastructure does } \\
\text { the data tie into staff list, operator's personal details, } \\
\text { loaning company's details, company's financial } \\
\text { information and propriety information? }\end{array}$ \\
\hline Internet reliability & $\begin{array}{l}\text { The amount of uptime to the network service as once the } \\
\text { network is down means accessing and controlling these } \\
\text { machines, data feedback transmissions may be lost? }\end{array}$ \\
\hline
\end{tabular}

Overall, the sample size, statistical significance convention limitations, anonymous positive feedback received from the dashboard users supported in validating the cost model's outputs. It was inferred that the online dashboard provided significant support for SMEs to consider exploring the path towards PdM. Due to the significant acquisition cost of PdM architecture and extended maintenance of both computer and physical MT, the need arises for collaborations among SMEs via the proposed DNC PdM architecture to reduce unit MT costs and gain collectively from economy of scale and scope on a shared network. In summary this paper presents the study's contribution in the following manner:

- Proposed a cost effective PdM DNC system architecture for SME CNC machine shops that predicts cost savings ranging from $£ 22,804-£ 48,585$ over a range of $1-5$ CNC MTs

- Affirmed PdM's additional tangible value creation for SME CNC machine shops with potential reduction in MFR which also reduces MDC, MLC and MOE for the MTs

- Introduces opportunities for further exploratory research within the PdM subject area taking into account the perspective of SMEs, since they greatly contribute to UK's GDP and over 50\% of participants expressed interest in the research outcome to show their curiosity towards the subject area 


\section{Acknowledgement}

The authors would like to appreciate the colleagues Macvil J. Carvalho and Sumit Dilip Pawale for their assistance with data collection.

\section{References}

1. Ross, S. (2008). The industrial revolution (London: Evans).

2. More, C. (2000). Understanding the industrial revolution (London: Routledge).

3. Freeman, C., and Louça, F. (2001). As time goes by: From the industrial revolutions to the information revolution (Oxford: Oxford University Press).

4. Schwab, K. (2017). The fourth industrial revolution (New York: Crown Publishing Group).

5. Laird, K. (2017). Understanding the digital transformation called industry 4.0. Plastics Engineering $73,24-28$.

6. Bokrantz, J., Skoogh, A., Berlin, C., and Stahre, J. (2017). Maintenance in digitalised manufacturing: Delphi-based scenarios for 2030. International Journal of Production Economics 191, 154-169.

7. Selcuk, S. (2017). Predictive maintenance, its implementation and latest trends. Proceedings of the Institution of Mechanical Engineers, Part B: Journal of Engineering Manufacture 231, 1670-1679.

8. Mourtzis, D., and Vlachou, E. (2018). A cloud-based cyber-physical system for adaptive shop-floor scheduling and condition-based maintenance. Journal of Manufacturing Systems 47, 179-198.

9. Monostori, L., Kádár, B., Bauernhansl, T., Kondoh, S., Kumara, S., Reinhart, G., Sauer, O., Schuh, G., Sihn, W., and Ueda, K. (2016). Cyber-physical systems in manufacturing. CIRP Annals Manufacturing Technology 65, 621-641.

10. Peng, Y., Dong, M., and Zuo, M.J. (2010). Current status of machine prognostics in condition-based maintenance: a review. The International Journal of Advanced Manufacturing Technology 50, 297313.

11. Toh, K.T.K., and Newman, S.T. (1996). The future role of DNC in metalworking SMEs. International Journal of Production Research 34, 863-877.

12. Ruschel, E., Santos, E.A.P., and Loures, E. de F.R. (2017). Industrial maintenance decision-making: A systematic literature review. Journal of Manufacturing Systems 45, 180-194.

13. Garg, A., and Deshmukh, S.G. (2006). Maintenance management: literature review and directions. Journal of Quality in Maintenance Engineering 12, 205-238.

14. Ridgway, K., Clegg, C.W., and Williams, D.J. (2013). The Factory of the Future - (Future of Manufacturing Project: Evidence Paper 29).

15. March, S.T., and Scudder, G.D. (2017). Predictive maintenance: strategic use of IT in manufacturing organizations. Information Systems Frontiers, 1-15.

16. Haroun, A.E. (2015). Maintenance cost estimation: application of activity-based costing as a fair 
estimate method. Journal of Quality in Maintenance Engineering 21, 258-270.

17. Mobley, R.K. (2002). An Introduction to Predictive Maintenance 2nd ed. (Boston: ButterworthHeinemann).

18. Platfoot, R. (2014). Practical Analytics for Maintenance Teams Using Computerised Maintenance Management System Work History. Australian Journal of Multi-Disciplinary Engineering 11, 91103.

19. Galar, D., Sandborn, P.A., and Kumar, U. (2017). Maintenance Costs and Life Cycle Cost Analysis (Boca Raton: CRC Press).

20. Zhang, Z., Wang, Y., and Wang, K. (2013). Fault diagnosis and prognosis using wavelet packet decomposition, Fourier transform and artificial neural network. Journal of Intelligent Manufacturing $24,1213-1227$.

21. Wang, J., Wang, P., and Gao, R.X. (2013). Tool life prediction for sustainable manufacturing. In 11th Global Conference on Sustainable Manufacturing, G. Seliger, ed. (Berlin: Universitätsverlag der TU Berlin), pp. 230-234.

22. Liu, C., Vengayil, H., Zhong, R.Y., and Xu, X. (2018). A systematic development method for cyberphysical machine tools. Journal of Manufacturing Systems 48, 13-24.

23. Baheti, R., and Gill, H. (2011). Cyber-physical Systems. In The Impact of Control Technology, T. Samad and A. M. Annaswamy, eds. (IEEE Control Systems Society), pp. 161-166.

24. MacDougall, W. (2014). Industrie 4.0: Smart Manufacturing for the Future (Berlin).

25. Lee, J., Bagheri, B., and Kao, H.-A.A. (2015). A Cyber-Physical Systems architecture for Industry 4.0-based manufacturing systems. Manufacturing Letters 3, 18-23.

26. Brettel, M., Friederichsen, N., Keller, M., and Rosenberg, M. (2014). How Virtualization, Decentralization and Network Building Change the Manufacturing Landscape: An Industry 4.0 Perspective. International Journal of Mechanical, Aerospace, Industrial, Mechatronic and Manufacturing Engineering 8, 37-44.

27. IBM (2016). Are your preventive maintenance efforts wrenching away precious resources? Time to listen to your machines.

28. Mobley, R.K. (2001). Plant Engineer's Handbook (Boston: Butterworth-Heinemann).

29. Enparantza, R., Revilla, O., Azkarate, A., and Zendoia, J. (2006). A life cycle cost calculation and management system for machine tools. 13th CIRP International Conference on Life Cycle Engineering 2, 717-722.

30. Parida, A., Kumar, U., Galar, D., and Stenström, C. (2015). Performance measurement and management for maintenance: A literature review.

31. Reina, A., Kocsis, Á., Merlo, A., Németh, I., and Aggogeri, F. (2016). Maintenance Decision Support for Manufacturing Systems Based on the Minimization of the Life Cycle Cost. Procedia CIRP 57, 674-679. 
32. Kans, M., and Ingwald, A. (2008). Common database for cost-effective improvement of maintenance performance. International Journal of Production Economics 113, 734-747.

33. Cheng, T., Zhang, J., Hu, C., Wu, B., and Yang, S. (2001). Intelligent machine tools in a distributed network manufacturing mode environment. International Journal of Advanced Manufacturing Technology 17, 221-232.

34. Bryman, A., and Bell, E. (2011). Business Research Methods 3rd ed. (Oxford: Oxford University Press).

35. Cohen, J. (1988). Statistical power analysis for the behavioral sciences 2nd ed. (Hillsdale: Laurence Erlbaum Associates).

36. Bawa, H.S. (2004). Manuacturing Processes (New Delhi: Tata McGraw-Hill Education).

37. Panik, M.J. (2012). Statistical inference: a short course (Hoboken: Wiley).

38. Shagluf, A., Longstaff, A.P., and Fletcher, S. (2015). Derivation of a cost model to aid management of CNC machine tool accuracy maintenance. Journal of Machine Engineering 15, 17-43.

39. Curwin, J., and Slater, R. (2013). Quantitative methods for business decisions 6th ed. (Andover: Thomson Learning).

40. Shagluf, A., Parkinson, S., Longstaff, A.P., and Fletcher, S. (2018). Adaptive decision support for suggesting a machine tool maintenance strategy. Journal of Quality in Maintenance Engineering 24, 376-399.

41. Tabachnick, B.G., and Fidell, L.S. (2007). Using multivariate statistics 5th ed. (Boston: Allyn \& Bacon).

42. Ungureanu, A.L., Stan, G., and Butunoi, P.A. (2016). Reducing maintenance costs in agreement with CNC machine tools reliability. IOP Conference Series: Materials Science and Engineering 145, 1-6.

43. Robertson, J. (2012). Likert-type scales, statistical methods, and effect sizes. Communications of the ACM 55, 6.

44. Houshyar, A. (2005). Reliability and Maintainability of Machinery and Equipment, Part 2: Benchmarking, Life-Cyclecost, and Predictive Maintenance. International Journal of Modelling and Simulation 25, 1-11.

45. Wilkinson, L. (2006). Revising the Pareto Chart. The American Statistician 60, 332-334.

46. Houshyar, A. (2004). Reliability and Maintainability of Machinery and Equipment, Part 1: Accessibility and Assessing Machine Tool R\&M Performance. International Journal of Modelling and Simulation 24, 201-210.

47. Todman, J.B., and Dugard, P. (2001). Single-case and Small-n Experimental Designs 1st ed. (New York: Routledge).

48. Okoh, C., Roy, R., and Mehnen, J. (2017). Predictive Maintenance Modelling for Through-Life Engineering Services. Procedia CIRP 59, 196-201.

49. Mislick, G.K., and Nussbaum, D.A. (2015). Cost estimation: methods and tools (Hoboken: Wiley). 
50. Gu, C., He, Y., Han, X., and Xie, M. (2017). Comprehensive cost oriented predictive maintenance based on mission reliability for a manufacturing system. In 2017 Annual Reliability and Maintainability Symposium (RAMS) (Orlando: IEEE), pp. 1-7.

51. Needy, K.L., Nachtmann, H., Roztocki, N., Warner, R.C., and Bidanda, B. (2003). Implementing Activity-Based Costing Systems in Small Manufacturing Firms: A Field Study. Engineering Management Journal 15, 3-10.

52. Patil, R.B., Kothavale, B.S., Waghmode, L.Y., and Joshi, S.G. (2017). Reliability analysis of CNC turning center based on the assessment of trends in maintenance data. International Journal of Quality \& Reliability Management 34, 1616-1638.

53. Moeuf, A., Pellerin, R., Lamouri, S., Tamayo-Giraldo, S., and Barbaray, R. (2018). The industrial management of SMEs in the era of Industry 4.0. International Journal of Production Research 56, $1118-1136$.

54. Kim, J.H. (2015). How to Choose the Level of Significance: A Pedagogical Note How to Choose the Level of Significance: A Pedagogical Note.

55. Figueiredo Filho, D.B., Paranhos, R., da Rocha, E.C., Batista, M., da Silva Jr., J.A., D. Santos, M.L.W., Marino, J.G., Rocha, E.C. da, Batista, M., Silva Jr., J.A. da, et al. (2013). When is statistical significance not significant? Brazilian Political Science Review 7, 31-55.

56. Yip, P.S.L.L., and Tsang, E.W.K.K. (2007). Interpreting dummy variables and their interaction effects in strategy research. Strategic Organization 5, 13-30.

57. Searle, S.R., and Udell, J.G. (1970). The Use of Regression on Dummy Variables in Management Research. Management Science 16, B-397-B-409.

58. Marais, K.B., and Saleh, J.H. (2009). Beyond its cost, the value of maintenance: An analytical framework for capturing its net present value. Reliability Engineering and System Safety 94, 644657.

59. Wright, O. (2018). Business population estimates for the UK and regions 2018 (London).

60. Vishwakarma, G. (2017). Sample Size and Power Calculation. In Research Methodology, pp. 1-21. 


\section{Appendix A: Survey Questions \& Response Summary}

\begin{tabular}{|c|c|c|c|c|c|c|c|c|c|c|c|c|}
\hline \multicolumn{4}{|c|}{ Q1 } & \multicolumn{4}{|c|}{ Q2 } & \multicolumn{2}{|c|}{ Q3 } & \multicolumn{3}{|c|}{ Q4 } \\
\hline 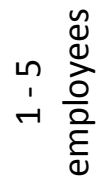 & 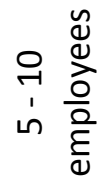 & 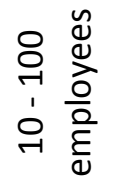 & 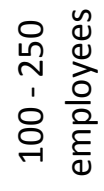 & 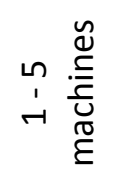 & 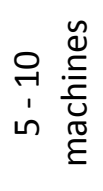 & 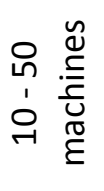 & 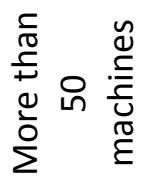 & $\begin{array}{l}\text { D } \\
\stackrel{2}{2} \\
\text { ob }\end{array}$ & $\begin{array}{l}\bar{\Xi} \\
\stackrel{心}{\Xi} \\
\stackrel{\Xi}{\Xi}\end{array}$ & 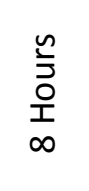 & 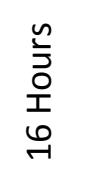 & 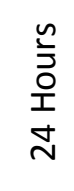 \\
\hline $21 \%$ & $5 \%$ & $26 \%$ & $47 \%$ & $47 \%$ & $21 \%$ & $32 \%$ & $0 \%$ & $21 \%$ & $79 \%$ & $37 \%$ & $26 \%$ & $37 \%$ \\
\hline
\end{tabular}

\begin{tabular}{|c|c|c|c|c|c|c|c|c|c|c|}
\hline \multicolumn{6}{|c|}{ Q5 } & \multicolumn{5}{|c|}{ Q6 } \\
\hline $\begin{array}{l}8 \\
8 \\
\circ \\
\circ \\
\stackrel{4}{4}\end{array}$ & $\begin{array}{l}\stackrel{8}{\circ} \\
\text { Оิ } \\
\text { फ }\end{array}$ & $\begin{array}{l}8 \\
8 \\
\circ \\
\ddot{\oplus}\end{array}$ & \begin{tabular}{l}
8 \\
8 \\
8 \\
\multirow{4}{4}{}
\end{tabular} & 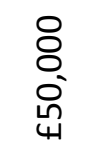 & $\begin{array}{l}8 \\
8 \\
\circ \\
0 \\
4\end{array}$ & $\begin{array}{l}\mathscr{c} \\
\stackrel{0}{z}\end{array}$ & 离 & $\begin{array}{l}\stackrel{0}{\tilde{\nu}} \\
\stackrel{\sim}{\sim}\end{array}$ & 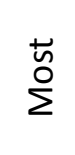 & $\overline{\bar{\alpha}}$ \\
\hline $21 \%$ & $11 \%$ & $21 \%$ & $11 \%$ & $21 \%$ & $16 \%$ & $68 \%$ & $11 \%$ & $11 \%$ & $5 \%$ & $5 \%$ \\
\hline
\end{tabular}

Q1 What is the total number of employees in your organisation?

Q2 How many CNC machines do your company currently operate?

Q3 Do you currently own your CNC machines or lease them from another vendor?

Q4 What is the total operating hours of your CNC machines per day?

Q5 What is your current total annual maintenance costs for CNC machines in $\mathrm{fGBP}$ ?

Q6 Are any of your CNC machines use data collection sensors or are internet connected?

\begin{tabular}{|c|c|c|c|c|c|c|c|c|c|}
\hline \multicolumn{5}{|c|}{ Q7.1 } & \multicolumn{5}{|c|}{ Q7.2 } \\
\hline $\begin{array}{l}\text { 崩 } \\
\sum_{0}^{3}\end{array}$ & 3 & $\begin{array}{l}\stackrel{0}{ \pm} \\
\frac{0}{0} \\
\frac{0}{0} \\
0 \\
\Sigma\end{array}$ & $\frac{c}{.00}$ & 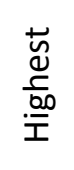 & 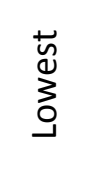 & oె & $\begin{array}{l}\stackrel{0}{0} \\
\frac{0}{0} \\
\frac{0}{0} \\
0 \\
\Sigma\end{array}$ & 点 & 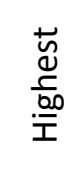 \\
\hline $26 \%$ & $16 \%$ & $47 \%$ & $11 \%$ & $0 \%$ & $11 \%$ & $47 \%$ & $11 \%$ & $21 \%$ & $11 \%$ \\
\hline
\end{tabular}

\begin{tabular}{|c|c|c|c|c|c|c|c|c|c|}
\hline \multicolumn{5}{|c|}{ Q7.3 } & \multicolumn{5}{|c|}{ Q7.4 } \\
\hline $\begin{array}{l}\text { 芯 } \\
\sum_{0}^{\Delta}\end{array}$ & 30 & $\begin{array}{l}\frac{0}{0} \\
\frac{\pi}{0} \\
\frac{0}{0} \\
\frac{0}{2}\end{array}$ & 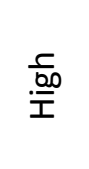 & 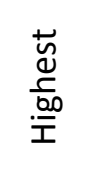 & $\begin{array}{l}\text { 峛 } \\
\sum_{0}^{3}\end{array}$ & 3. & $\begin{array}{l}\stackrel{0}{0} \\
\frac{0}{0} \\
\frac{0}{0} \\
\frac{0}{\Sigma}\end{array}$ & $\frac{\frac{c}{00}}{\overline{\underline{x}}}$ & 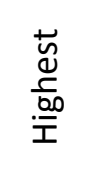 \\
\hline $11 \%$ & $21 \%$ & $26 \%$ & $26 \%$ & $16 \%$ & $5 \%$ & $26 \%$ & $42 \%$ & $5 \%$ & $21 \%$ \\
\hline
\end{tabular}

7 On a scale from 1- 5, (1 being the lowest, and 5 being the highest) how would you rate each of the following? Q7.1 Current maintenance costs of your CNC machines compared to total operations costs

Q7.2 Loss of productivity due to maintenance

Q7.3 Impact of down time due to machine breakdown

Q7.4 Effectiveness of your current maintenance processes 


\begin{tabular}{|c|c|c|c|c|c|c|c|c|c|c|c|}
\hline \multicolumn{5}{|c|}{ Q8 } & \multicolumn{3}{|c|}{ Q9 } & \multicolumn{4}{|c|}{ Q10 } \\
\hline 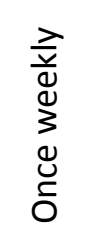 & 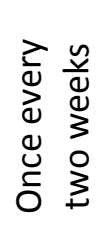 & 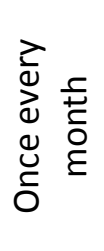 & 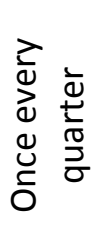 & 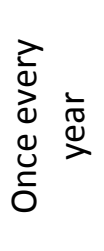 & 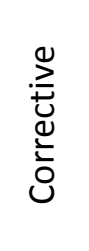 & 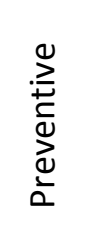 & 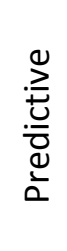 & 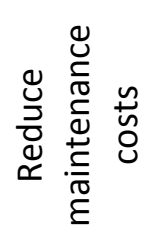 & 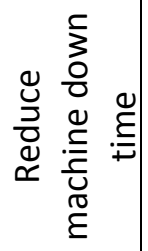 & 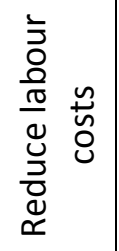 & 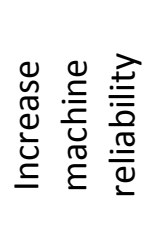 \\
\hline $16 \%$ & $32 \%$ & $26 \%$ & $21 \%$ & $5 \%$ & $21 \%$ & $74 \%$ & $5 \%$ & $25 \%$ & $25 \%$ & $25 \%$ & $25 \%$ \\
\hline
\end{tabular}

Q8 On average, how often do you face a machine stop due to a performance issue or breakdown?

Q9 What is your current maintenance strategy for your CNC machines?

Q10 What were your primary motives of choosing a predictive maintenance approach (Check all that applies)?

\begin{tabular}{|c|c|c|c|c|c|c|c|c|c|c|c|}
\hline \multicolumn{5}{|c|}{ Q11 } & \multicolumn{5}{|c|}{ Q12 } & \multicolumn{2}{|c|}{ Q13 } \\
\hline $\begin{array}{c}00 \\
0 \\
\circ \\
1 \\
-1\end{array}$ & $\begin{array}{l}\text { o̊ } \\
\text { } \\
1 \\
0 \\
\stackrel{-1}{1}\end{array}$ & $\begin{array}{c}\text { ㅇ } \\
\circ \\
m \\
1 \\
0\end{array}$ & 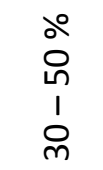 & 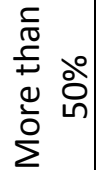 & $\begin{array}{c}\stackrel{0}{0} \\
\circ \\
\stackrel{-}{1} \\
1 \\
-1\end{array}$ & 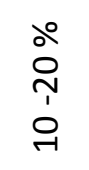 & $\begin{array}{c}\text { ১0 } \\
\circ \\
m \\
1 \\
0 \\
0\end{array}$ & $\begin{array}{l}\text { ㅇ } \\
\text { 울 } \\
1 \\
1 \\
0\end{array}$ & 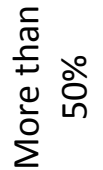 & $\stackrel{\mathscr{y}}{\nu}$ & z \\
\hline $0 \%$ & $0 \%$ & $0 \%$ & $100 \%$ & $0 \%$ & $100 \%$ & $47 \%$ & $11 \%$ & $21 \%$ & $11 \%$ & $58 \%$ & $42 \%$ \\
\hline
\end{tabular}

Q11 On average, what was your maintenance costs per machine as a percentage of total operations costs before using predictive maintenance?

Q12 On average, what is your current maintenance costs per machine as a percentage of total operations costs after using predictive maintenance?

Q13 Do you consent that I want to be contacted with a summary of the research results when the research is concluded on September 2018? 